AL-AZHAR UNIVERSITY

BULLETIN OF THE FACULTY

OF

LANGUAGES \& TRANSLATION

جامعة الأزهر

مجلة كاية اللغات والترجمة

\title{
المعاني الدلالية للمورفيم (JI) في اللغة السواحيلية
}

د. حسام محمد رمضيان إبراهيم

مدرس اللغة السواحيلية وآدابها

معهد البحوث والدراسات الإفريقية ودول حوض النيل

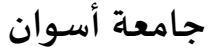




\title{
المعاني الدلالية للمورفيم (JI) في اللغة السواحيلية
}

\author{
حسام محمد رمضان إبراهيم \\ قسم اللغات الإفريقية، معهد البحوث والدراسات الإفريقية ودول حوض النيل، جامعة أسوان، أسوان، مصر . \\ البريد الإلكتروني: drhr55@yahoo.com
}

يهذف هذا البحث إلى دراسة المعاني الدلالية للمورفيم (ji) في صوره المختلفة في اللغة السواحيلية. وذلك من خلال روايتين للكاتب كين واليبورا. وهما رواية (Siku njema) ورواية (Nasikia Sauti ya Mama). وقد توصل البحث إلى أن المورفيم (ji) يأني للتعبير عن التكبير، والتصغير، واسم الفاعل، واسم المعنى، والانعكاسية. وقد ظهر من خلال البحث أن المعنى الدلالي للمورفيم (ji) هو تكثيف المعنى، والدلالة على التأكيد، وإزالة اللبس الذي ينشأ عند حذفه. ويتميز المورفيم (ji) بأنه بضفي على الجملة نوعا من البلاغة، لأنه عند استخدامه في الجملة يعطي معنى زائدا لغرض بلاغي. الكلمات المفتاحية: المعاني الدلالية، المورفيم (ji)، التكبير والتصغير ، اسم الفاعل، اسم المعنى، الانعكاسية، التوكيد، اللغة السواحيلية

\section{Semantic Meanings of the Morpheme (ji) in Swahili Language}

Hossam Mohamed Ramadan Ibrahim

Department of African Languages, Institute of African and Nile States Researches and Studies, Aswan University, Aswan, Egypt.

Email: drhr55@yahoo.com

\section{Abstract:}

This research aims to study the semantic meanings of the morpheme (ji) in its various forms in the Swahili language. This is through two stories written by Ken Walibora. They are (Siku njema) and (Nasikia Sauti ya Mama). This research found that the morpheme (ji) comes to express the magnification, miniaturization, agent noun, deverbative noun, and reflexivity. Results showed that the semantic meaning of the morpheme (ji) was the intensification of the meaning, the indication of confirmation and remove the confusion that arises when deleted. The morpheme (ji) is distinguished by giving the sentence a form of rhetoric, because when used in the sentence it gives plus meaning to the rhetorical purpose.

Key words: Semantic Meanings, Morpheme (ji), Magnification, Miniaturization, Agent Noun, Deverbative Noun, Reflexivity, Affirmation, Swahili Language 


\section{مقدمة - - مقة}

من الجدير بالأكر أن اللغة السواحيلية تولي اهتماماً خاصاً بالسوابق واللواحق في الكلمة (1)، ومن ثم تنتاول هذه الدراسة أحد المورفيمات في اللغة السواحيلية، وهو المورفيم (ji). والذي يستخدم مرة كسابقة ومرة أخرى كلاحقة. وستركز الدراسة بالبحث والتحليل على المعاني الدلالية للضمير (ji) عند استخدامه في اللغة السواحيلية في صوره المختلفة. حيث يستخدم هذا المورفيم في التعبير عن التكبير، والتصغير، واسم الفاعل، وللتعبير عن اسم المعنى. كما يأني المورفيم (ji) كضمير انعكاسي(*) (Kiambishi Kirejeshi). (2) أي أن الذي قام بأداء الفعل والذي وقع عليه الفعل هو الفاعل نفسه. يعتبر المورفيم (ji) ميزة تتميز بها اللغة السواحيلية وخاصية من خصائصها. ومن ثم فان للمورفيم (ji) أهميته في اللغة السواحيلية، وتتجلى أهميته فى نقاط خمس هي: الأولى: يسهل الإنسجام النطقي له؛ لأنه مقطع صوتي صغير يتكون من صوتين الأول صامت والثاني صائت. الثانية: يكثر استخدامه في اللغة السواحيلية. حيث يعتبر المورفيم (ji) من المورفيمات التي تخص بنية الكلمة وتُحدِثُ تَغيرًا دلالياً بالكلمة. الثالثة: يُستخدم لتقديم معاني أكثر دقة وأقوى 1 للمزيد راجع: "البو ادىء و اللواحق وتأثير ها على بنية الكلمات فى اللغة السو احيلية "، مجدى محمد بيومى: رئه

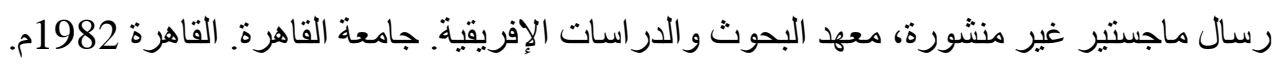

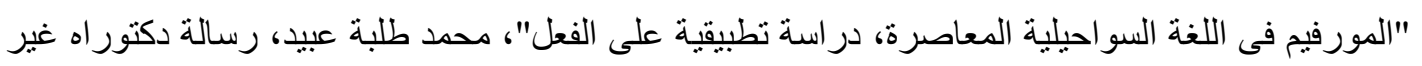

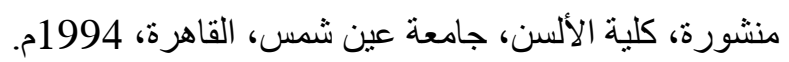

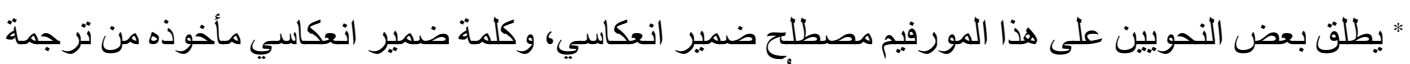

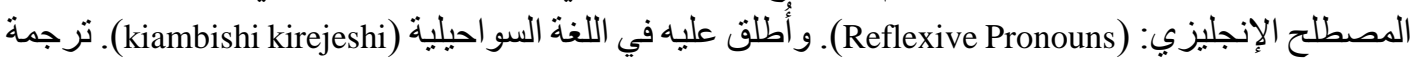

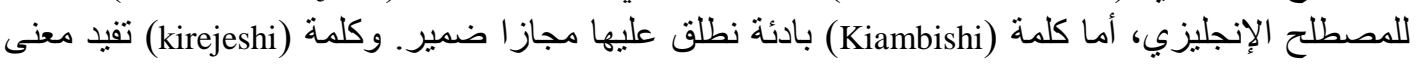

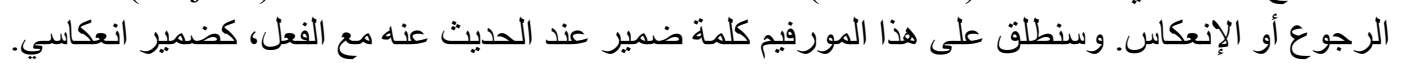

" simplified Swahili" Wilson,Peter, Longman,1985

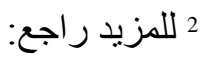

"Swahili grammar (Including Intonation)" Ashton, E.O. (1944-1974): Longman.

"Sarufi Tangulizi ya Kiswahili, Sarufi Maumbo", Wesana- Chomi E., Idara ya Uchapishaji, Tasisi ya Lugha, Sebha, Libya 1989.

“Sarufi mpya", Mohamed A. Mohomed; Press and Publicity Centre, Dar-es-Salaam, Tanzania 1986. 
تعبيرا. رابعا: يستخدم بدلا من الاسم لتجنب تكرار نفس الاسم في الجملة. خامسا: إضفاء صبغة بلاغية على الجملة. وتأني أهمية هذا البحث في أنه يسلط الضوء على المورفيم (ji) في اللغة السواحيلية بالبحث والتحليل؛ وذلك من أجل رصد طرق استخدامه في الجملة السواحيلية والمعاني الدلالية له. وبيان كيفية الوصول إلى هذه المعاني الدلالية المختلفة للضمير (ji) في الجملة السواحيلية بطريقة صحيحة. تكمن مشكلة المورفيم (ji) في أنه مورفيم يستخدم في تركيبات نحوية متعددة ويدل على معاني دلالية محددة، ولكي يتم التوصل إلى هذه الدلالة؛ فلابد من نوافق هذا المورفيم مع البنية التركيبية في الجملة. ولكن إذا لم يحدث هذا التوافق فلن يؤدي المورفيم (ji) المعنى الدلالي الموضوع من أجله، ومن ثم جاء هذا البحث ليعرض استخدامات هذا المورفيم مع الجملة حتى يحدث توافق ما بين المورفيم (ji) والجملة؛ للوصول للغرض الدلالي الموضوع من أجله هذا المورفيم. ولكي يتم التوصل إلى هذه المعاني الدلالية سيتم دراسة هذا المورفيم في صور مجيئه المختلفة في اللغة السوحيلية، وهذا من شأنه أن يمهد إلى التوصل إلى المعنى الدلالي العام للمورفيم (ji)، بعد اكتمال عملية التوافق التركيبي في الجملة (*).

"وللمزيد فى ذلك يُنظر: النحو العربي والدرس الحديث، ص 119، عبده الراجحي: دار النهضة العربية للطباعة

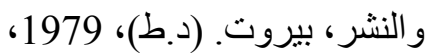
قو اعد تحويلية للغة العربية، صلي، 23، محمد علي الخولي: المملكة العربية السعودية، الرياض، ط 1، دار المريخ

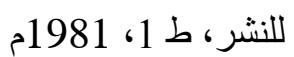

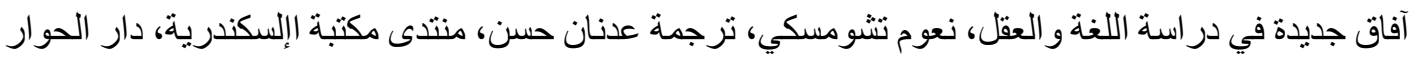
للنشر و التوزيع السورية، ط1، القو اعد التحويلية في الجملة العربية، عبد الحليم بن عيسى، دار الكتبة الكب العلمية، بيروت، لبنان، ط1 ، 2011م. Kwa zaidi unaweza kuangalia:

المدارس النحوية، شوقي ضيف، القاهرة، 1976.

"Utangulizi wa Lugha na Isimu", Besha, Ruth Mfumbwa. Dar es Salaam University press, Dar es Salaam, 1994.

"Mitindo ya Kiswahili Sanifu" Mwansoko,H.J.M, Dar es salaam university press, Dar es salaam . .(1991) 
ولتوضيح ماذهبت إلبه الدراسة نسوق المثال التالي من مادة الدراسة التي بين أيدينا(*): من

$$
\text { رواية (Siku Njema) }
$$

Ukweli ukidhihiri uongo hujitenga. $\left({ }^{3}\right)$

إذا ظهر الحق زهق الباطل. - إ.

والمعنى التفسيرى للجملة (إذا ظهر الحق فمن المؤكد يزهق الباطل). هذه الجملة تتضمن المورفيم (ji) والذي يفيد الانعكاس ـ أي التعبير عن النفس ـ في الكلمة (hujitenga) حيث أتى المورفيم (ji) قبل جذر الفعل (tenga) والزمن (hu). فالمعنى الدلالي للمورفيم (ji) في الجملة يفيد التأكيد. أي أن الباطل سيزهق بالتأكيد. فالقاعدة أن المورفيم (ji) إذا جاء في جملة الثرط يدل على أن جواب الثرط مؤكد حدوثه. يمكن ملاحظة أن توافق الزمن (hu) - الذي يدل على العادة - مع المورفيم (ji) في الجملة، يدل على أن حدوث جواب الثرط أمر مؤكد وعادة ما يحدث، ولا مجال للثك فيه. فقد حدث توافق بين المورفيم (ji) وبنية الجملة من حيث التركيب النحوي والمعنى الدلالي. ومن ثم سنقوم الدراسة بإيضاح هذه المعاني الدلالية وبيان كيف يأني هذا المعنى المقصود

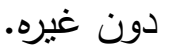

وسترصد الدراسة أيضا النمط الذي يأتي عليه المورفيم (ji). ففي المثال السابق المورفيم (ji) قد سبقه الزمن (hu) فالقاعدة هنا أن الزمن (hu) من الأزمنة التي قد تسبق المورفيم (hu) (ji) وهذا التلاصق البنيوي يعطي معنى توكيدي أعمق. وقد ورد هذا التركيب البنيوي مع (ji) في المثل السوحيلي: (Paka akidhihiri panya hujitenga). إذا ظهر القط فمن المؤكد يختفي الفأر من تلقاء نفسه.

"Sentences in Swahili:Astudy of their internal relationships" Maw,Joan, SOAS.University of London 1969.

$$
\text { * انظر مادة الدر اسة: ص } 6 .
$$

3 "Siku njema" P 18. Walipora, Ken Longhorn Publishers (K) Ltd. , Nairobi, Kenya., chapa cha kwanza, 1996. Toleo, 2012. 
فالخلاصة هنا أن المعنى الدلالي للمورفيم (ji) يفيد التأكيد على وقوع الحدث في جملة جواب الشرط المشنملة على ضمير الثرط (ki). ويأتي الزمن (hu) في جملة جواب الثرط مع ضمير الانعكاس (ji) ليفيد أن هذا الأمر عادة ما يحدث. ومن الملاحظ أن التلاصق البنيوي بين (hu) و (ji) يدل على علاقة التأكيد على حدوث الفعل في المستقبل. فالجملة الثرطية التي تحمل معنى الثرط في المستقبل قد يكون فيها شك في حدوث جواب الثرط، ولكن عند وجود (ji) والزمن (hu) بؤكد على أن هذا قد حدث مثله في الماضي فلا شك في حدوثه في المستقبل. فهو يحمل معنى التقة والطمأنينة من أن جواب الشرط متحقق بالفعل.

ولنأخذ مثالا آخر يعالج مسألة توافق المورفيم (ji) مع بنية الجملة من خلال مادة البحث من رواية (Nasikia Sauti ya Mama):

- Baba alipokuwa hayupo, vijana wote nyumbani kwetu-wavulana na wasichana walijihisi huru. $\left({ }^{4}\right)$

- عندما يغيب الأب، فجميع الثباب بمنزلنا أولاد وبنات يشعرون بالحرية. جاء المورفيم (ji) في كلمة (walijihisi) بمعنى يشعرون أنفسهم، ليعبر عن الإنعكاس أي وقوع الفعل على الفاعل. قد توافق مع الزمن الماضي (li) والفاعل الغائب للجمع (wa)، حيث يدل المعنى الدلالي للمورفيم (ji) على تأكيد حدوث الفعل. ومن الملاحظ أن المعنى الدلالي للمورفيم (ji) قد توافق مع الفعل يشعر الذي بدل على أن الثعور قد نبع من أنفسهم بالتأكيد. اعتمدت مادة هذه الدراسة على بعض الأمثلة من الأبحاث اللغوية في اللغة السوحيلية، والمواضع التي ورد فيها المورفيم (ji) في روايتين سواحيليتين للروائي كين واليبورا. وهما: "Siku njema" Ken Walipora, Longhorn Publishers (K) Ltd. , Nairobi, Kenya., chapa cha kwanza, 1996. Toleo, 2012.

4 "Nasikia Sauti ya Mama" P 71. Ken Walipora, Longhorn Publishers (K) Ltd., Nairobi, Kenya., chapa cha kwanza, 2014. Toleo, 2016. 
"Nasikia Sauti ya Mama" Ken Walipora, Longhorn Publishers (K) Ltd.

Nairobi, Kenya., chapa cha kwanza, 2014. Toleo, 2016.

اتخذت الدراسة المنهج الوصفي Descriptive approach منهجا للبحث اللغوي في هذه الدراسة لأنه" يتجه أولاً إلى الجمع والوصف، ثم إلى التحليل والتعليل"(5) حيث تتقق هذه الدراسة مع "المنهج الوصفي Descriptive approach الذي لم يُين على أسس من المنطق، وإنما اهتم بالنظر في الاستعمال اللغوي وتسجيله وتحليله على نحو ما ورد في النص، دون الإغراق في الجدل، أو الخوض في التعقيدات والتعليلات الفلسفية والمنطقية"(6). تقوم الدراسة برصد الصور التي يأتي عليها المورفيم (ji) وإيراد الأمتلة الدالة على ذللك، ثم توضيح المعنى الدلالي بعد إجراء عملية التحليل اللغوي للكلمة التي ورد فيها المورفيم (JI). وسيركز البحث على الأساسيات التالية:

1- ذكر الصور التي يأتي عليها المورفيم (ji) 2- أمثلة من واقع مادة الدراسة على تلك الصور . 3- دراسة تلك الأمثلة من الناحية التركييية والدلالية، من أجل الخروج بنتائج عامة تصف الحالات التي يأني عليها المورفيم (ji) والمعاني الدلالية لها. وتهدف هذه الدراسة إلى ما يلي: بيان الصور التي يأني عليها المورفيم (ji) في الجملة في اللغة السوحيلية. حيث أن الخلل في فهم التركيب اللغوي في الجملة ينتج عنه خلل في إيصال المعنى المراد. التوصل إلى المعنى الدقيق المقصود من المورفيم (ji) في الجملة عند استخدامه. وذللك لتحاشي سوء الفهم؛ بالإضافة إلى التعرف على المعاني الدلالية له في اللغة السواحيلية ودوره في إضفاء البلاغة عند التعبير به في الكلام.

5"اللغة الإعلامية علم الإعلام اللغوي"، ص 195، عبد العزيز شرف، الناشر المركز الثقافي الجامعي-

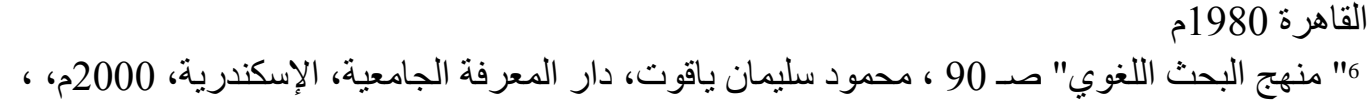
وللمزيد في ذلك يُنظر : "البحث العلمي" صـ 81. سهير بدر، دار دار المعارف، القاهرة، 1982م، الإنة 
بدأت هذه الدراسة بمقدمة تمثل مدخلاً تمهيدياً لفهم موضوع الدراسة، ثم عرض لأهمية البحث ومشكلته ومادة الدراسة والمنهجية التي تقوم عليها الدراسة، ثم جاءت الدراسة في مبحثثن كالتالي:

$$
\text { المبحث الأول: دلالات المورفيم (ji) في الأسماء الثاني: دلالات المورفيم (ji) في الأفعال }
$$

أخيراً تعرض الدراسة لأهم النتائج والتوصيات، ثم ثَتبت المراجع العربية والأجنبية. المبحث الأول: دلالات المورفيم (ji) في الأسماء

أولأ: التكبير (7)

يأتي التكبير في اللغة السوحيلية عل مستوبين: المستوى الأول بتجريد الإسم المراد تكبيره من سابقة فصيلته الأصلية فتقول مثلا:

Guu Dudu حشرة كبيرة Goma طبلة كبيره يمكن اثتقاق التكبير من أي اسم بتجريده من سابقة فصيلته. وبمجرد تجريده يندرج نحويا تحت فصيلة (JI - Ma) منل:

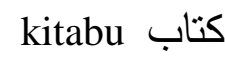
tabu مجلد matabu مجلدات ubawa جناح bawa mabawa أجنحة كبيرة أما المستوى الثاني من التكبير : يكون عن طريق تجريد الإسم من سابقة فصيلته الأصلية ثم إضافة المورفيم (ji) في بداية الاسم

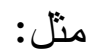
jiguu قدم ضخمة جدا jidudu حشرة ضخمة جدا jigoma طبلة ضخمة جدا jitabu مجلد ضخم جدا

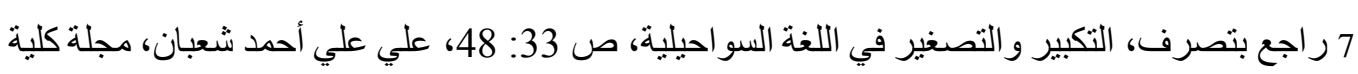
اللغات والترجمة، جامعة الاز هر ، العدد 18، 1988

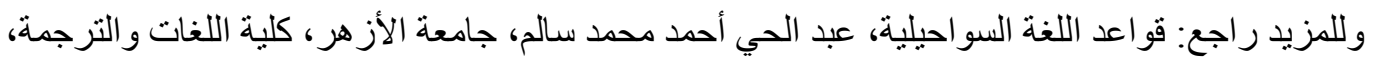

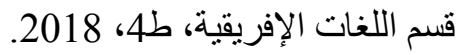
راجع أيضاً: Mohamed Abdulla Mohamed, Modern Swahili Grammar, East African Publishers, 2001. 
أما الأسماء التي تتدرج تحت فصيلة (ji - ma) فليس لها إلا مستوى تكبير واحد بإضافة السابقة : من (ji)

jisanduku صندوق كبير jigari

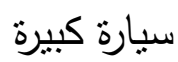

ثنانياً: التصغير (8)

تأني صيغة التصغير من الأسماء وحيدة المقطع في السواحيلية بإضافة المقطعين (ki+ji)

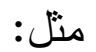

$\mathrm{Tu}$ kijitu:

قزم

Tسرة خشب :

Cho kijicho مسد أو حقد (عين حقيره حسودة)

ونأخذ مثالا من رواية (Nasikia Sauti ya Mama)

Baba alikuwa miongoni mwa watu wachache waliokuwa na redio kwetu kijijini. P.3 كان أبي من قلائل الناس الذين يمتلكون مزياعاً في قريتنا.

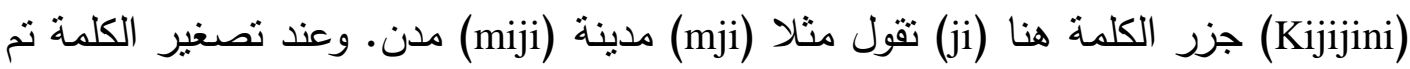
إضافة (ki+ji) لتصبح الكلمة (kijii) بمعنى قرية. وتم إضافة (ni) في آخر الكلمة لتعبر عن المكانية وتترجم بمعنى (في) أي في القرية. ونأخذ مثالا آخر من رواية (Nasikia Sauti ya Mama)

Goli ya kijiti ya mpira wa miguu.P. 7

مرمى كرة القدم المصنوع من كسرة خشب. أما الجذور متعددة المقاطع فالتصغير منها على مستويين: المستوى الأول: بإضافة السابقة (ki) إلى الجذر منل:

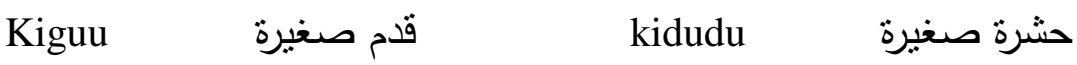

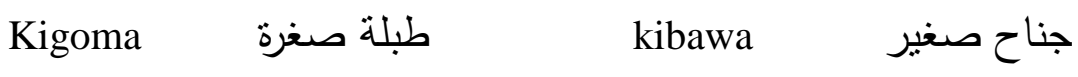

8 ر راجع بتصرف، التكبير و التصغير في اللغة السو احيلية، ص 33: 48 48، علي علي أحمد شعبان، مجلة كلية

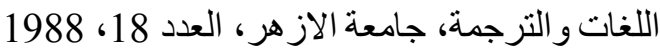


ونأخذ مثالا من رواية (Nasikia Sauti ya Mama)

Nilitafakari sana kuhusu kisanduku hicho kidogo. P.4

فكرت كثير بشأن هذا الصندوق الصغير .

فالكلمة أصلها (sanduku) تم إضافة (ki) قبلها للالالة على التصغير . أما الأسماء من فصيلة (ki -vi) فتكون بإضافة المقطعين (ki+ji) مثل: كتيب، كتاب صغير kijitabu

أما المستوى الثاني مع الجذور متعدد المقاطع يكون بإضافة السابقتين (ki + ji) منل: Kijiguu

فالوظيفة الصرفية والدلالية للمقطع (ji) تتمثل في إزالة اللبس الصرفي والدلالي الذي قد ينشأ عند حذفه. وقد اعتبر علي علي شعبان أن (ji) ظاهرة عرضية في اللغة السوحيلية لا تفسير لها. وأضاف أيضا بأن وظيفة المقطع (ji) بالإضافة إلى أمن اللبس الصرفي والدلالي هو ki ) تكثيف معنى التصغير المتضمن في المقطع (ki) مع الجذور التي لا تتدرج تحت فصيلة ( - vi والدلالي الذي ينشأ عن حذفه(9). فالخلاصة هنا أن المورفيم (ji) يأتي مع السابقة (ki) في التصغير بغرض دلالي هو إعطاء معنى مكثف للتصغير، وكذلك الأمر في التكبير بتكثيف المعنى في التكبير • حيث أن وظيفة (ji) الدلالية هي تكثيف المعنى في التصغير وتكثيف المعنى في التكبير • وأيضا إزالة اللبس الصرفي والدلالي الذي ينشأ عند حذفه.

9 راجع بتصرف، المرجع السابق. ص 33 : 48. 
يأتي اسم الفاعل في اللغة السوحيلية عن طريق اشتقاق الاسم من الفعل باستخدام المورفيم (ji) في نهاية جذر الفعل وبإضافة بادئة فصيلة الكائنات الحية (M - wa). وهذا المورفيم يفيد أن شخصًا قد اعتاد على فعل شئ أي صاحب مهنة أو حرفة ما يعمل بها، على سبيل المثال: Imba مغني mwimbaji

Tangaza مذيع mtangazaji مذيع

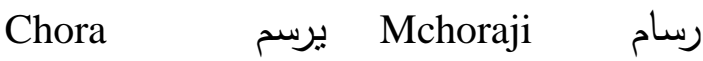

ونأخذ مثالا من رواية (Nasikia Sauti ya Mama)

Nilitamani kuwa mtangazaji wa redio. P. 4

تمنيت أن أكون مذيعا بالإذاعة.

ترى الدراسة أن المعنى الدلالي هنا للمورفيم (ji) عند إضافته في نهاية جذر الفعل المسبوق ببادئة فصيلة الكائنات الحية (M - wa)، ليعبر عن اسم الفاعل. هو إعطاء معنى دلالي إضافي للفعل عند تحويله إلى اسم فاعل. يتمثل في تكثيف لمعنى الفعل، بإعطاء معنًى زائدا عليه. حيث أن القائم بالفعل لم يقم بأداء الفعل مرة واحدة إنما اعتاد القيام به. وأصبح صفة ملازمة

\section{رابعاً: اسم المعنى يعبر عن مهنة أو حرفة}

يستخدم هذا المورفيم (ji) في اشتقاق الإسم من الفعل ليعبر عن اسم لفعل أو لعمل يتم القيام به، فيعبر عن مهنة أو حرفة أو مهارة ما. وذللك عند إضافة المورفيم (ji) في نهاية جذر الفعل وإضافة سابقة فصيلة أسماء المعاني (u) فبل جذر الفعل تقول مثلا: Sema

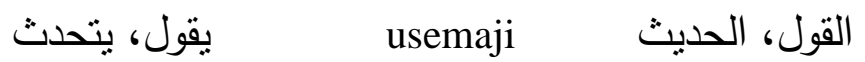

10 John Habwe, Peter Karanja, Misingi ya Sarufi ya Kiswahili, Phoenix Publishers Ltd., Nairobi, Kenya 2004, P.96

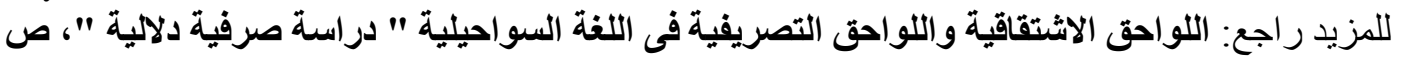

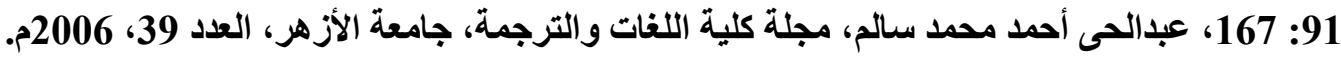




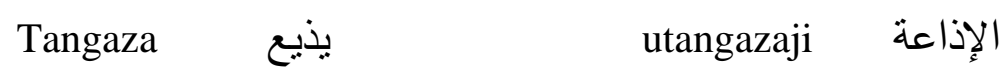

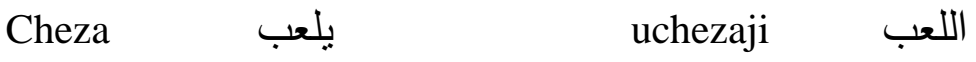

ونأخذ منالا من رواية (Nasikia Sauti ya Mama)

Kila muhula niliongoza katika somo la sanaa ya uchoraji. P. 13

كنت الرائد في كل فصل دراسي في مادة فن الرسم. كلمة (chora) يرسم (uchoraji) الرسم.

ففي الأمتلة السابقة اتضح أن الاسم قد اشتق من الفعل بإضافة المورفيم (ji). والمعنى الدلالي للمورفيم (ji) هنا هو تكثيف لمعنى الفعل ليصبح سمة لفعل يتكرر كثيرا. وبهذا ترى الدراسة أن المورفيم (ji) عند إضافته إلى نهاية الفعل أعطى معنى زائدا لمعنى الفعل، أي نم اشتقاق معاني جديدة من الفعل، كاسم الفاعل ليعبر عن القائم بالفعل، والاسم من الفعل ليعبر عن المهنة. فالمعنى الدلالي للمورفيم (ji) عند إضافته للفعل يفيد تكثيف للمعنى. المبحث الثاني: دلالات المورفيم (ji) في الأفعال

\section{التعبير عن الانعكاسية}

يستخدم المورفيم (ji) كضمير انعكاسي في اللغة السواحيلية ("kiambishi kirejeshi "ji) وهو عبارة عن أداة تقع في الفعل لتعبر عن أن الذي قام بالفعل هو الفاعل بنفسه. وعندما يستخدم هذا المورفيم كضمير انعكاسي فالغرض منه التوكيد. ويقع الضمير الانعكاسي في الفعل بعد الزمن وقبل جذر الفعل مباشرة مثال ذلك كأن تقول: (Nitajifanya hivyo) بالتأكيد سأقوم بهذا بنفسي أو من المؤكد أني سأقوم بهذا. والمعنى الدلالي للضمير (ji) الانعكاسي هو التأكيد على أن الذي قام بأداء الفعل والذي وقع عليه الفعل هو الفاعل نفسه وبعينه. ولزيادة التأكيد قد يأتي بعد الضمير (ji) كلمة نفس أو عين، ولزيادة التأكيد أيضا يتغير النبر الصوتي عند النطق بالضمير (ji) وعلى كلمة النفس والعين في الجملة. مثال ذلك . من المؤكد أني سأقوم بهذا بنفسي. (Nitajifanya hivyo mwenyewe) 
ويلزم عند استخدام هذا الضمير في الكلام، أن يتوافق مع بنية الجملة، ومنطقية المعنى الدلالي مع الواقع، حتى وإن كانت بنية الجملة سليمة. أي مراعاة المعنى الدلالي العام للجملة، على لئ سبيل المثال: (samaki wamejivua wenyewe) السمك صاد نفسه بنفسه. فهذه الجملة لم تسنقم في المعنى. لأن السمك لا يصطاد نفسه. فالمعنى الدلالي يجب أن يتوافق مع جميع أجزاء الجملة، ومن ثم فإن الجملة التي تشتمل على الضمير الانعكاسي (ji) يجب أن تتوافق جميع أجزائها ليحصل لنا المعنى التام فنقول (Wavuvi wamejivua wenyewe samaki) اصطاد الصيادون السمك بأنفسهر. وستعرض الدراسة الصور التي يأتي فيها الضمير (ji) الانعكاسي في الجملة السوحيلية في حالة الإفراد والجمع. فيما يلي:

\section{(أ): توافق ضمير الانعكاس مع الجملة في حالة الإفراد}

ستعرض الدراسة تحليلا لأمتلة من كل رواية من روايتي مادة البحث كنموذج؛ لبيان الصور التي يأتي عليها الضمير (ji) للتعبير عن الإنعكاسية مع ضمائر الفاعل المختلفة وباقي أجزاء الجملة. وقد يزيد الإستشهاد بالأمتلة أو ينقص على حسب ما تقتيه الدراسة في كل نقطة من نقاط البحث. وذلك منعا للإطناب المفرط أو الإيجاز المخل. ومنعا للخروج عن مقتضيات الدراسة.

أولاً: التوافق مع مفرد فصيلة الأثخاص (M-WA) التوافق مع ضمير المتكلم: (NI): مثال مما ورد من مادة الدراسة في رواية (Siku Njema):

- Nilipojua kusoma nilijikusuru kuzisoma tungo adhimu za Kiswahili nilizopata kukumbana nazo, vitabuni na magazetini. (Siku Njema) P. 5 
- فلما عرفت القراءة لا جرم (*) قررت قراءة المؤلفات السواحيلية العظيمة لدي من كتب

$$
\text { ومجلات. }
$$

فمن الملاحظ من خلال هذه الجملة أن الأفعال قد تعددت، واتحد فيها الفاعل وهو ضمير المتكلم (ni) واتحد فيها الزمن وهو الزمن الماضي (1i). وقد جاء الضمير الانعكاسي (ji) في فعل واحد من هذه الأفعال، وهو(nilijikusuru) قررت. وهذا بدل على أن المعنى الدلالي للضمير الانعكاسي (ji) يحصل في الجملة التي يتعدد فيها الفعل في الزمن الماضي ويتحد فيها الفاعل ولا يلزم تكراره في الجملة مع باقي الأفعال. كما أن الفعل الذي قد ذُكر فيه الضمير (ji) هو الفعل المراد التأكيد عليه بأن الذي قام بهذا الفعل هو الفاعل بنفسه فضلا عن باقي هذه الأفعال. وذلك لدفع الثكك وإزالة التوهم في ذهن المتلقي من أن الذي قام بالفعل ليس الفاعل بنفسه. وأيضا لأهمية الفعل الذي تم التأكيد عليه. والغرض الدلالي للضمير (ji) الانعكاسي هنا في الجملة توضيح مدى العزيمة الصادرة من المتكلم على القيام بالأمر بنفسه دليل على أن على عاتقه مسئوليه كبيرة تتمنل في قراءة كل المؤلفات التي لديه دليل على كثرتها لديه. فقد جاء الضمير (ji) بمعنى زائد على الفعل وهو التأكيد. ودفع توهم السامع عن أن الفاعل لم يقم هو بالفعل. كما أن التأكيد هنا أيضا بغرض بيان الفخر والإعتزاز بالقيام بهذا الفعل. وعلى ذلك يمكن القول بأن المعنى الدلالي للضمير (ji) الانعكاسي هو التأكيد وقد يتأنى في فعل واحد في الجملة التي يتعدد فيها الفعل ويتحد فيها الفاعل مع الزمن. منال آخر من رواية (Siku Njema): - من

- Nilijiuliza maswali mengi kuhusu kazi ya majanajike yale nisipate jibu. (Siku Njema) P. 53.

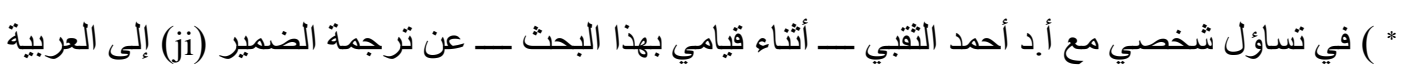

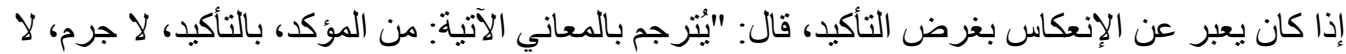

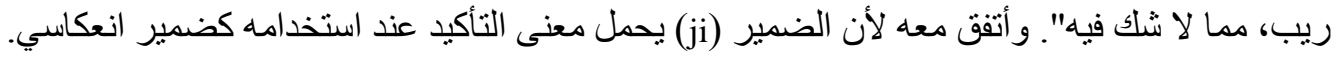


أسئلة كثيرة) حول عمل هؤلاء النسوة ذوي الخلق السيء ولم

$$
\text { أحصل على إجابة. }
$$

جاء الضمير الانعكاسي (ji) هنا في كلمة (nilijiuliza) سألت نفسي بغرض التأكيد.

ويظهر من خلال هذا المثال السابق أن المعنى الدلالي للضمير الانعكاسي (ji) يأتي على

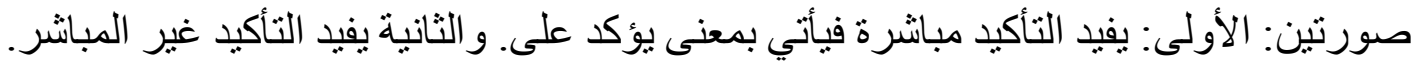
حيث يأتي ضمير الانعكاس بمعنى النفس أو الذات دلالة على التوكيد ولكن بطريقة غئ غير مباتشرة

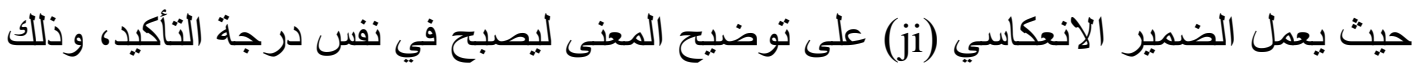
يتحدد عن طريق المعنى الدلالي للكلمة التي ورد فيها ضمير الانعكاس، و والسياق الدالالي للجملة.

أمثلة أخرى من رواية (Siku Njema): - (

- Siku nyingi baada ya kuhamia kwa mjomba nilijihisi nimepepeana mno. P.18

$$
\text { - شعرت في نفسي بعد مغادرة العم بعدة أيام بأنني في تذبذب شديد. }
$$

- Nilipojibanza kipembeni nitazame vizuri nilishangaa zaidi. P. 21

$$
\text { - عندما انزوت نفسي جانبا نظرت جيدا فتعجبت بشدة. }
$$

- Nami nikajinyamazia huku nikikikumbuka kituko kilichokuwa kimetokea punde kwa fadhaa. P. 53

$$
\text { - فأنا أهدئ نفسي إذا ما تذكرت ما حدث من فظاعة منذ لحظة. }
$$

- Sikuamini rafiki yangu Rashid amekufa mpaka nilipojikabilisha moyo kuingia katika chumba cha kuhifadhia maiti katika hospitali ya Makadara keshoye. P. 76.

- لم أصدق وفاة صديقي رشيد حتى تملكت نفسي للاخول في غرفة حفظ الموتى في مستشفى مادار اكا في الغداة.

- Bali nilijirudi mwenyewe na kusimamisha rukwama. P.78.

$$
\text { - لكنني عدت بنفسي وأوقفت عربة اليد. }
$$


Kwa muda mrefu nimekuwa najiambia kuwa habari ya kufa kwake ni ndoto mbaya tu ambayo ingekwisha niamkapo. P. 96.

- - كنت منذ فترة طويلة أخبر نفسي أن خبر موته حلم سيئ للغاية فما أن ينتهي أستيقظ.

Nilijisikia mnyonge na dhalili. P. 101.

$$
\text { - - منثعر في نفسي بالضعف و المذلة. }
$$

- Nikajifunza funzo; ukipokea msaada, kuwa tayari kutoa maana kutoa ni kikoa. P. 109.

- تعلمت بالتأكيد درسًا، إذا ما تلقيت أنت مساعدة، فكن مستعدا للعطاء بمعنى أن العطاء بالتناوب.

- Nilibisha mlangoni lakini sikuitikiwa. Nikasita kidogo, kisha nikajitoma ndani. P. 124.

- طرقت الباب ولم يجب أحد علي. ترددت قليلا، ثم اندفعت بنفسي بقوة إلى الداخل.

- Nilikuja polepole nikajibanza nje ukutani na kukusikiliza toka awali mpaka akheri. P. 129.

-

من الملاحظ في الأمتلة السابقة أن الضمير الانعكاسي جاء على صورتين إما مؤكدا للفاعل على قيامه بالحدث، وإما مؤكدا على الحدث بأن من قام به هو الفاعل الذي يعود عليه الضمير الانعكاسي.

ففي كلمة (nilijihisi) ضمير انعكاسي هنا جاء للنأكيد على الفاعل، فجاء الضمير الانعكاسي ليوضح حال الفاعل نفسه من الحدث. وعلى هذا يمكن القول بأنه عندما يلحق الضمير الانعكاسي بالأفعال الدالة على الإحساس والثعور إنما يكون ضمير الانعكاس مؤكدا وموضحا لحال الفاعل من الحدث. وهذا ما عبر عنه الضمير (ji) في كلمة (Nilijisikia mnyonge) شعرت نفسي بالضعف، فهنا ضمير الانعكاس يؤكد على حال الفاعل من الإحساس بالضعف، 
فضمير الانعكاس يلفت انتباه المستمع أو المتلقي بأن الفاعل في حالة تستحق الانتباه والثعور بها فهي دعوة للإحساس والثعور بما شعر به الفاعل. فيعدد القائل إلى التأكيد بضمير الانعكاس للفت الانتباه وجعل المستمع يعيش نفس إحساس الفاعل. حيث أنه عند الحديث عن النفس قد يظن المتلقي أو السامع أن المتكلم قد يبالغ في حديثه ولكن عند التأكيد برجع السامع عن ظنه إلى التصديق بكلام المتكلم. وأيضا في المثال:

Mpaka nilipojikabilisha moyo kuingia katika chumba cha kuhifadhia maiti

حتى تملكت نفسي للاخول في غرفة حفظ الموتى. هنا تأكيد على الفاعل. لجذب المستمع نحو الثعور بما بشعر به المتكلم. الصورة الثانية من خلال الأمتلة السابقة أن ضمير الانعكاس قد أكد على الحدث أكثر من تأكيده على فاعل الحدث. وظهر ذلك في Nami nikajinyamazia) أنا أهدئ نفسي. فالتأكيد هنا عilipojibanza (لمى الحدث وهو التهئة أكثر من التأكيد على القيام بالحدث. وأيضا في كلمة (kipembeni حتى يشعر المثلقي بالحدث الذي يتحدث عنه المتكلم. وظهر جليا في المثال: Najiambia kuwa habari ya kufa kwake ni ndoto mbaya tu

$$
\text { أُحَدِّثُ نفسي أن خبر موته حلم سيئ للغاية. }
$$

فحور التأكيد هنا على الحدث. وهو الإخبار عن الوفاة. ومن الملاحظ أن التأكيد قد ركز على الحدث لنقله على النفس. وهنالك ملاحظة أخرى أن عند التأكيد على الحدث قد يكون الفاعل ليس من العادة القيام بهذا الحدث يتضح هذا في المثال: - ال

Bali nilijirudi mwenyewe na kusimamisha rukwama.

فليس من عادة المتكلم العودة إلى إيقاف العربة. ويؤكد هذا كلمة (bali) التي ابتدأت بها الجملة. وأيضا في جملة (kisha nikajitoma ndani.) ثم اندفعت بنفسي بقوة إلى الداخل، حيث ليس من العادة الاندفاع في الدخول. إنما التأكيد هنا على الحدث الذي ليس من العادة القيام به لنتبيه المتلقي إليه ولفت انتباهه إلى الحدث. 
وقد يكون التأكيد على الحدث دون الانتباه إلى الفاعل لجذب المستمع نحو الحدث وهذا ما يمكن ملاحظته في (Nikajifunza funzo). تعلمت بالتأكيد درسا. فالتأكيد على تعلم الدرس لما له من أهمية تستدعى من المتلقي الانتباه إليه. توافق ضمير الانعكاس مع ضمير الفاعل للمتكلم المفرد والزمن: مثال من رواية: (Nasikia Sauti ya Mama):

Kisha ningecheza na wenzangu nikacharukwa hadi nikajisahau. (Nasikia Sauti ya Mama, p. 7)

$$
\text { - ثم ما أن ألعب مع رفاقي فأنغمس حتى أنسى نفسي. }
$$

m - (ji) مكرر مجيئ ضمير الانعكاس (ji) مع الفاعل المفرد المتكلم (wa ومع الزمن الماضي في الجملة أكثر من الأزمنة الأخرى. وهذا يعطي إثارة بأن المعنى الدلالي لضمير الانعكاس يكثر مجيؤه مع الزمن الماضي للنأكيد على الماضي. ومن الملاحظ أيضا أن ضمير الانعكاس جاء في فعل واحد في الجملة ولم يتكرر في كل الأفعال في الجملة التي جاء ضمير الانعكاس فيها مؤكدا على فاعل الحدث. وقد أتى ضمير الانعكاس في هذه الجملة مع الفعل (Sahau) بمعنى ينسى ليؤكد أن المنكلم قد نسى تماما نفسه أثثاء اللعب. فالنسيان قد صدر من المتكلم ووقع عليه أيضا. والغرض من التأكيد هنا هو وصف نسيان الذات في الانغماس في اللعب يدل على معنى زائد على النسيان وهو الانهماك الثديد إلى حد الخروج عن الانتباه إلى ما يشغل النفس. دليل على أن اللعب قد استغرق جميع حواسه وقلبه. فهو تصوير بليغ عن طريق ضمير الانعكاس يزيد الجملة بلاغة في التعبير. ويجعل المنلقي يشعر بالفاعل. ويعيش معه الحدث. والملاحظ هنا أن ضمير الانعكاس جاء في جملة مركبة واتحد فيها الفاعل المفرد للمتكلم، وعلى هذا يمكن استتناج أن ضمير الانعكاس يلحق بالفعل الذي يدل على الإحساس والثعور عندما تتكرر الأفعال في 
الجملة مع الفاعل المفرد المنكلم. حيث أن أفعال الإحساس والثعور تحتاج إلى ضمير الانعكاس لتؤكد على الفاعل أكثر من التأكيد على الحدث في الأفعال الأخرى. أمنتة أخرى من رواية: (Nasikia Sauti ya Mama):

- Ilimuradi nilijifunza mengi katika shule hii ya mama aliyoniwekea kama msingi wa maisha yangu ya halafu. P. 47.

\section{- - فالقصد أنني تعلمت بنفسي الكثير في مدرسة أمي فجعلتها لي كأساس لحياتي القادمة.}

- Katika akili yangu ya kitoto isiyokuwa na shakashaka, palikuwa na kazi aina tatu zilizonisubiri katika mustakabali wangu baada ya kuhitimu masomo; mbili nilijichagulia mwenyewe, nyingine moja baba alinipendekezea. P. 3.

مما لا شكل في أن عقلي الطفولي اشتمل على أنواع ثلاثة من العمل كانت في انتظاري

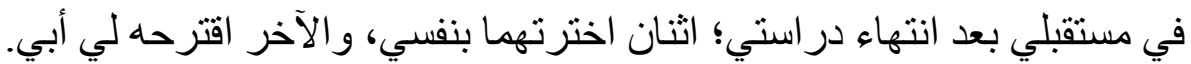

Ninapoisaka hazina ya kumbukumbu yangu naiona japo kwa utusitusi siku niliyojijua na kujitambua kwa mara ya kwanza kwamba mimi ni mimi. Hapana, sikumbuki mambo mengi yaliyotendeka siku hiyo, wala nilichokifikiria, nilichokitenda au kukisema. P. 14.

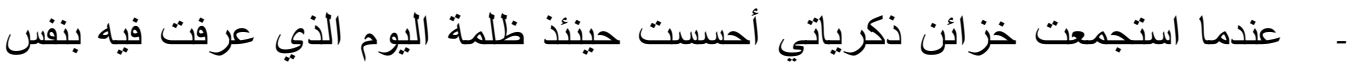

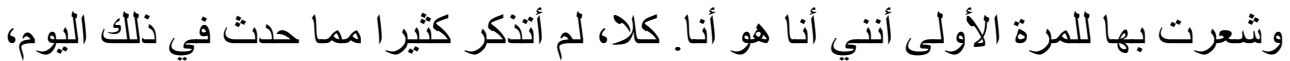

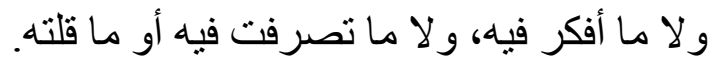

- Hata hivyo, vilevile nilipojiunga na shule ya msingi ya st. Joseph's na kurejea nyumbani na ripoti ya mwisho wa muhula iliyoonyesha nilikuwa ndimi wa mwisho darasani, yaani mnyonge wa wanyonge, niligarijika jinsi mama alivyonipokea bila ukali. P. 42, 43.

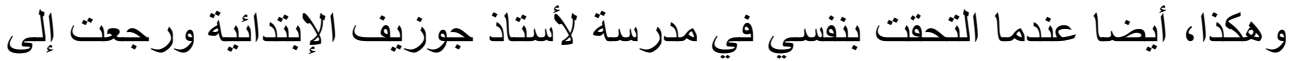

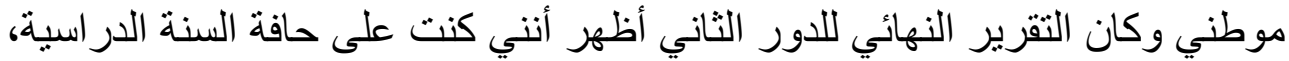
بمعنى أضعف الضعفاء، لقد ذهلت من الطريقة التي استقبلتني بها أمي بدون تعنيف.

- Mathalani nilijifunza kwamba, dunia haikuwa na watu waliozungumza lugha yangu tu. P. 47. 
- مثلا تعلمت بالفعل أن الدنيا لا تكون بالناس الذين بتحدثون لغتي فقط.

Kutoka kwa Mzee Kibii, nilijifunza faida ya kucheka. P. 57.

$$
\text { - تعلمت بالفعل من السيد كيبي أهمية الضحك. }
$$

- Aidha nilijifunza hatari ya kulewa ovyo na kujigeuza sinema kwa wengine. P. 57.

$$
\text { - - أيضا تعلمت بالتأكيد خطورة أن أسكر وأتحول بنفسي إلى سينما للآخرين. }
$$

- Mambo mema katika silka yangu nimejifunza kutokana kwake; mabaya nimejifunza mwenyewe katika shule nyingine rasmi na zisizokuwa rasmi. P.58.

- من الأمور الطيبة في أخلافي أنني تعلمت بنفسي منك، و السوء تعلمته بنفسي في كثير من المدارس الحكومية و غير الحكومية.

- Nikajishangaza mwenyewe na kuwashangaza wengine mpaka wakanipigia saluti. P. 80.

$$
\text { - تعجبت في نفسي بشدة وتعجب الآخرون حتى ضربو الي تعظيما. }
$$

- Kwa hiyo Jumatano moja baada ya vipindi vya masomo, nikajipa kusema kwenye majadiliano ambayo wanafunzi wote walihudhuria. P. 84.

- وفي يوم الأربعاء بعد انتهاء البر امج الدر اسية، ألقيت بنفسي خطابا حو اريا حضره جميع

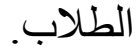

- Miaka mingi baadaye nilipojitosa kwenye bahari ya utunzi nilikinasa kisa hicho kwenye nudhuma hii ya "Risala" iliyokuwa kazi yangu ya kwanza kuchapishwa kwenye gazeti la Kenya leo Mei 23, 1983. p. 97.

بعد سنو ات، عندما أغرقت نفسي في بحر من النظم، نظمت قصة " رسالة " في هذا العمود، والتي كانت أول عمل لي نشرته جريدة كينيا اليوم، 23 مايو 1983.

- Nikajitoma ndani ya nyumba yetu na kukomelea mlango. P. 108.

$$
\text { - - اندفعت بنفسي بقوة إلى داخل منزلنا وأغلقت الباب. }
$$


- Mwaka huo wa 1976 nikajikuta kwenye kikosi kimoja cha riadha na Festo Makokha kuiwakilisha shule yetu kwenye mashindano ya shule za baraza la mji wa Kitale. P. 108, 109.

- وجدت نفسي في عام 1967 في أحد الفرق الرياضية مع فيستو ماكوخا نيابة عن مدرستنا في مسابقات مدارس مجلس مدينة كينالي.

- Naam, nikajiambia mwenyewe kwa mwenyewe papo kwa papo; Maskini bado hujawa mwanamume; labda gumegume. Mwanamume hujawa bado. P.131.

- حسنا، حدثت نفسي على الفور؛ المسكين ليس رجلا، ربما الحظ. فالرجل لم يصل بعد.

Najirudi mwenyewe. Makosa yangu mengi, sitaki kuongeza mengine zaidi.. p. 137.

$$
\text { - لا جرم عدت بنفسي. أخطائي كثيرة، لا أريد الزيادة عليها. }
$$

- Nikajizatiti kutupa ngumi moja hafifu, ngumi yangu ya mwisho katika shule ya msingi ya St. Joseph's ikampata Kadogo shavuni. Mwalimu Onyango, mwokozi wangu akahamaki na kuninyaka kibao kikali sana. P. 140.

- قررت بما لا شك فيه أن ألكم كادوجو في خده لكمة خفيفه، فتكون لكمتي الأخيرة في

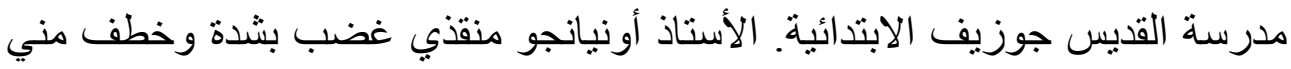
الخشبة بعنف شديد. القين شوزئ

من خلال الأمثلة السابقة يمكن ملاحظة ما يلي: موقع ضمير الانعكاس من الجملة.

أن ضمير الانعكاس يأتي مع الفاعل المتكلم المفرد، حيث قد يأتي في أول الجملة أو أوسطها أو آخرها دون أن يؤثر ذلك في المعنى الدلالي لضمير الانعكاس. فموقع

$$
\text { ضمير كلمة الانعكاس من الجملة لا يؤثر على المعنى الدلالي له. (mwenyewe) بعد ضمير الانعكاس: }
$$


إذا جاءت كلمة نفس (mwenyewe) بعد ضمير الانعكاس في الأفعال الدالة على الإحساس والثشعور فإنما هي تنل على أن ضمير الانعكاس جاء ليؤكد على الفاعل وجاءت كلمة نفس لنتؤكد على نفس المعنى أيضا.

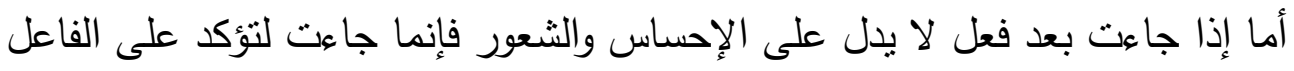

$$
\text { كثرة مجيء ضمل التأكيد في الجملة على الفاعل والحدث معاً. }
$$

يأتي ضمير الانعكاس (ji) مع الفعل (funza) ليؤكد على تحصيل العلم، وما بلاقيه المتعلم من عناء في تحصيله، ولذلك فالتأكيد هنا على الحدث، في المقام الأول ثُ يليه لئل

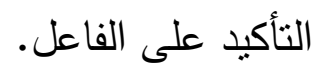

\section{التوافق مع ضمير المتكلم المنفي (si):}

Sikujisikitisha kuliko ilivyokuwa lazima kusikitika. (Siku Njema, p.19).

$$
\text { - لم أحزن نفسي أكثر مما ينبغي أن أحزن. }
$$

الغرض من الضمير الانعكاسي (ji) في كلمة (sikujisikitisha) هو التأكيد على ضمير المتكلم

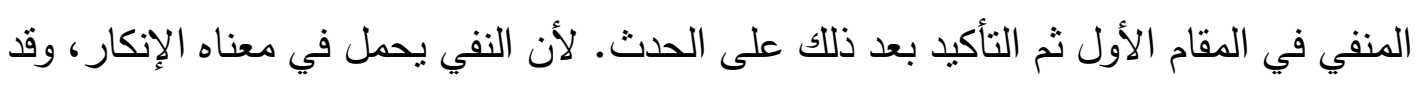
أتى ضمير الانعكاس ليؤكد على هذا الإنكار على الفاعل ثم بعد ذلك يؤكد على الحدث لأن المنفي. فالمعنى الدلالي لضمير الانعكاس (ji) في الجملة أن الفاعل لم يحزن في نفسه أكثر مما ينبغي.

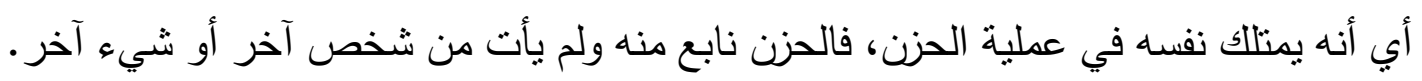
فالتأكيد على أنه يمتلك ناصية نفسه في التحكم في الحزن. مثال آخر من رواية (Siku Njema)

"Basi nenda kalale chumbani mwako," nikamwambia. "Peke yangu? Naogopa," akajibu. "Sijisikii kulala huko. Naogoba. Sijui naogopa nini, akasema. (Siku Njema, p.115). 
- أقول للك: " اذهب إلى النوم في حجرتلك،". أجاب قائلاً: " أبمفردي؟ فأنا خائف،". "

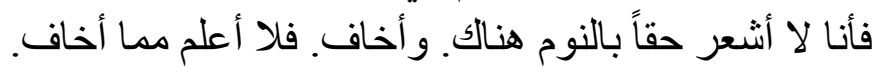

أنى ضمير الانعكاس مع النفي في كلمة (sijisikii) لا أنثعر في نفسي، فالمعنى الدلالي لضمير

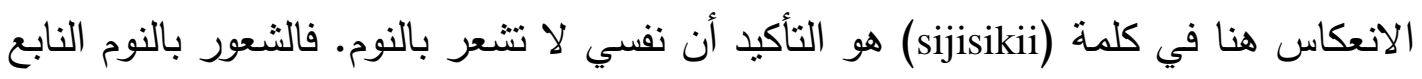

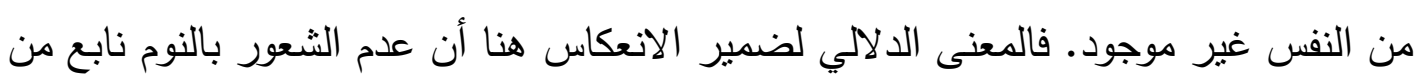
نفس المتكلم

فالنتيجة هنا أن توافق المعنى الدلالي لضمير الانعكاس في جملة الفاعل المفرد الشتنملة على

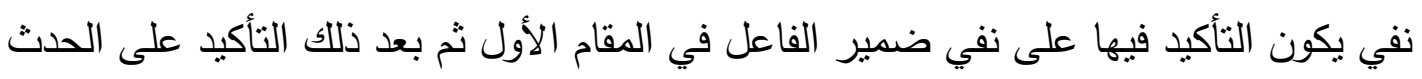
سواء مع أفعال الأحاسيس والثعور أو مع غيرها من الأفعال. التوافق مع ضمير المتكلم المنفي (si) المتبوع ب (mwenyewe):

مثال من رواية: (Nasikia Sauti ya Mama):

- Ulimi mzito kama nanga. Nikajaribu kusema; sikujisikia mwenyewe sembuse walionisikiliza. Nikaketi chini, nimefufumaa, uso sina pa kuuweka. P. 85.

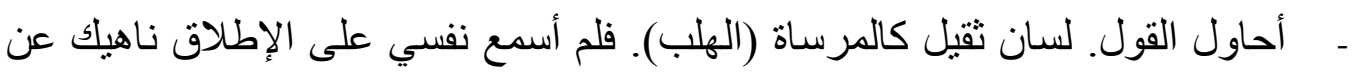

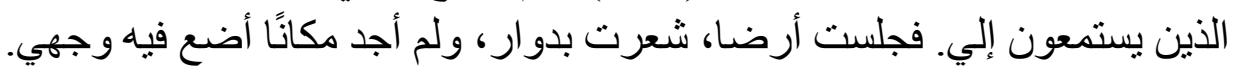

ضمير الانعكاس جاء في كلمة (sikujisikia) والتي تعني لم أسمع نفسي. فالمعنى الدلالي

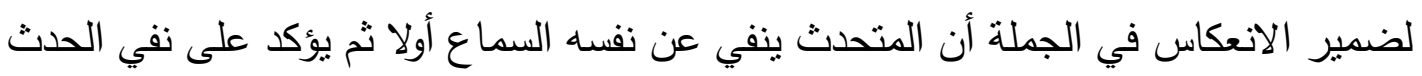

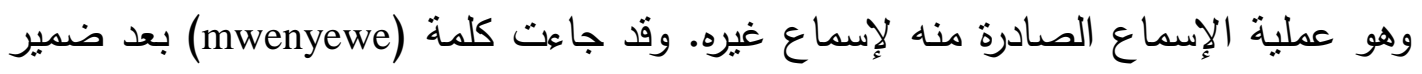

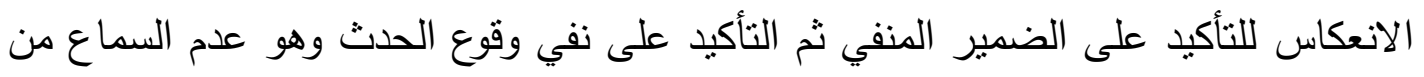

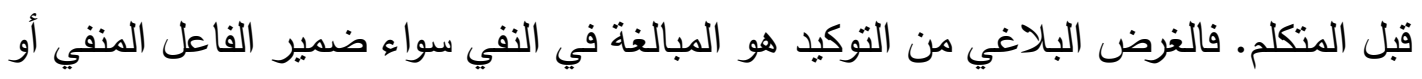
وقوع الحدث وهو السماع. فكلمة (mwenyewe) هنا لتقوية المعنى الدلالي لضمير الانعكاس مع الفاعل المتكلم المفرد المنفي. تصن. 


\section{التوافق مع ضمير المتكلم المنفي (si) المتبوع بفعل آخر في الجملة. \\ مثال من رواية: (Nasikia Sauti ya Mama):}

Kwa mara nyingine tena, wazee wangu na wakubwa zangu wote wakanisaidia nisijihurumie wala kujilaumu kwa matokeo yangu. P. 147.

- ـ أيضًا مرة أخرى، ساعدني كبار السن ورؤسائي جميعا ألا أثعر بالأسف على نفسي و لا ألومها على نتيجتي.

تكرر ضمير الانعكاس (ji) في هذه الجملة في كلمتين، الأولى: (nisijihurumie) بمعنى عدم الثعور بالأسف على نفسي، والكلمة الثانية: (kujilaumu) لا ألوم نفسي. فالمعنى الدلالي لضمير الانعكاس هنا يفيد التأكيد على النفي لضمير الفاعل، بمعنى أن المتحدث عليه أن يتحكم هو في الشعور بالأسف وفي لوم نفسه. والغرض هو التأكيد على النهي عن الأسف واللوم للنفس. وقد نوافق المعنى الدلالي لضمير الانعكاس مع الجملة التي تشنمل على ضمير للمتكلم المفرد المنفي. مع إمكانية أن يتكرر ضمير الانعكاس في الجملة ويأخذ نفس المعنى الدلالي لضمير الانعكاس أيضا.

\section{التوافق مع ضمير المخاطب المفرد (U):}

مثال ما ورد من مادة الدراسة في رواية (Siku Njema):

"La! Utakaa," alinikatiza kwa ushupavu. "Mwenyewe hapa umejithibitisha kuwa mtoto mwema. Najua umestahimili mengi. P. 41.

- ل إ أنت ستجلس، " قاطعني بشدة. " أنت هنا أنثبت بنفسك أنك طفل طيب. وأعلم إنك

$$
\text { تحملت كثيرا. }
$$

جاء ضمير الانعكاس مع ضمير المخاطب هنا في كلمة (umejithibitisha). للتأكيد على الحدث، وجاء قبل ضمير الانعكاس كلمة (mwenyewe) لتؤكد على القائم بالحدث. والمعنى الدلالي لضمير الانعكاس في الجملة أنت بنفسك أثبتَّ أنك طفل طيب. 
فيمكن ملاحظة التوافق الدلالي لضمير الانعكاس مع كلمة (mwenyewe) في الجملة. حيث تضاف كلمة (mwenyewe) قبل ضمير الانعكاس إلى الجملة عند قصد التأكيد على القائم بالحدث مع فعل ليس من أفعال الإحساس والثعور • مثال آخر من مادة الدراسة في رواية (Siku Njema):

- Umejibaidi kama ardhi ilivyojibaidi na mbingu. (Siku Njema, P. 95).

$$
\text { - - أبعدت نفسك كبُعد الأرض من السماء. }
$$

من الملاحظ هنا توافق ضمير الاتعكاس مع (kama) التي تقيد التشبيه في الجملة، وقد أتي ضمير الانعكاس في الفعل الذي أتى بعد (kama)، وذلك للتأكيد على الحدث. وهو الابتعاد. مثال من رواية: (Nasikia Sauti ya Mama) - (

- "Unajiringa kwa sababu wewe ni mtoto wa Hedi". Hedi ni kifipisho cha Hedimasta wa shule. P. 59.

- -تتباهي بنفسك لأنك ابن مدير المدرسة. (Hedi) اختصار لكلمة مدير المدرسة.

جاء ضمير الانعكاس في كلمة (unajiringa)" للتأكيد على القائم بالحدث. كلمة (ringa) معناها (يتباهي، يفتخر ، يختال). المعنى الدلالي هنا لضمير الانعكاس: الإحساس بالفخر . من الملاحظ أن كلمة نفس لا تأتي مع الأفعال التي تقيد الإحساس والثعور التي تحتوي على ضمير توكيد. مثال آخر من رواية: (Nasikia Sauti ya Mama):

- Mama. Utajifia hapa jamani, pahala papa hapa ambapo kwa maumivu ya sindano nilijivumbulia mimi ni mimi? Usife mama usife. P. 89.

ـ يا أمي أحقا ستتوفين هنا، أنا اختلقت لنفسي الألم الثديد في هذا المكان أفأنا هو أنا؟ فلا تموتي يا أمي لا تموتي التوني 
ضمير الانعكاس مع الفعل (kufa) جاء ليؤكد على القائم بالحدث. في أسلوب استفهامي لبيان هل سيقوم بالحدث أم لا. وعلى هذا فضمير الانعكاس إذا جاء في جملة استفهامية والفعل من أفعال الأحاسيس والثعور فإن التأكيد يكون على القائم بالحدث. أما ضمير الانعكاس (ji) مع كلمة (vumbilia) للتأكيد على الحدث. ومن الملاحظ أن ضمير الانعكاس (ji) قد يأتي مع الزمن المستقبل البسيط (ta)، ومع الزمن الماضي (li) وغير ذلك من الأزمنة. فلا يؤثر ذلك على المعنى الدلالي لضمير الانعكاس في الجملة. لأنه أصبح جزءا من جذر الفعل. مثال آخر من رواية: (Nasikia Sauti ya Mama):

- Njozi itimie. Lakini nasikia sauti ya mama ikisema, "Jidhibiti mwanangu usidhibitiwe." Laiti nisingekuwa na uwezo wa kuisikia sauti hii ya mama. P.137.

- اصبر إلى أن ينتهي. لكنتي أسمع صوت أمي يقول، " اضبط نفسك يا بني أم لا تنضبط." فيا ليتني ما كان لي القدرة على سماع صوت أمي هذا.

جاء ضمير الانعكاس (ji) في كلمة (jidhibiti) مع الفعل في صيغة الأمر التي تتطلب حذف الزمن، وحذف بادئة الفاعل. فالمعنى الدلالي لضمير الانعكاس هو التأكيد على الحدث وهو الانضباط وجاء في صيغة الأمر التي تحمل معنى النصح والإرشاد لأن صيغة الأمر حديث مباشر وواضح. فأمر الأم لابنها بالانضباط يحمل معنى التوجيه أيضا. وهو ما تحمله كلمة jidhibiti (بعد ضمير الانعكاس. فالمعنى يا بني انضبط أم لا تتضبط. ف (mwangngu) (mwangngu و للإِشارة إلى القائم بالحدث. 


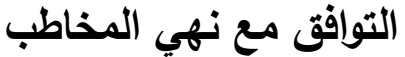

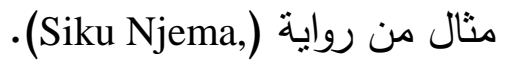

Kinywa chako mwenyewe, kisikusifu Fulani. Ni kheri sifa upawe, na wengine duniani. Sifa nyingi upaliwe, zijae pomoni. Mwenyewe usijisifu. P. 4.

- فكك نفسه، لا يُمدح من أحدا. فمن الأفضل أن تنال المديح من الآخرين في الدنيا. صفات

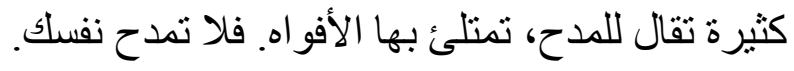

توافق ضمير الانعكاس مع ضمير الفاعل المخاطب والنهي في كلمة (usijisifu) وقد جاء قبلها كلمة (mwenyewe). فضمير الانعكاس جاء ليؤكد على الحدث، وقد سبقه (mwenyewe) ليؤكد على القائم بالحدث. ومن ثم فيؤدي ضمير الانعكاس عمله في الجملة مع النهي. والغرض نهي النفس عن المدح لأنه يؤدي إلى التكبر والمباهاة والتعالي على الآخرين ويكرهه المخاطب فأولى بك أن يمدحك الآخرون ولا تمدح نفسك. مثنال آخر من رواية (Siku Njema).

- "Wafanya kazi gani hawa?" nikauliza kwa umbea. Usijitie hamnazo Mswahili. Hawa wenzangu wamo kwenye chumo bwana, ushaona?. (Siku Njema, P.54).

- " من هؤ لاء العمال؟" أسألك دردشة. لا نشغل بالك يا أخي السو احيلي. إنهم أصدقائي في المكسب يا سيدي ألم نر ذلك؟

جاء ضمير الانعكاس في الكلمة (usijitie) ليعبر عن النهي عن الاهتمام. فالتأكيد على نهي القائم بالحدث فالمعنى الدلالي لضمير الانعكاس هنا: عليك أنت ألا تضع في بالك. أو لا تشغل باللك، لا تهنم. فالغرض الدلالي من ضمير الانعكاس هنا هو التأكيد على المخاطب ألا يشغل نفسه. أن عدم الاهتمام ينبع من نفس المخاطب ويقع عليه أيضا. أمثلة أخرى من رواية (Nasikia Sauti ya Mama):

- Usipojihadhari na hasira utahasirika. P. 53. 
- - لم تلتوخى نفسك الحذر من الغضب فستغضب.

جاء ضمير الانعكاس للمخاطب المفرد في صيخة النهي في (usipojihadhari) للتأكيد على الحدث وهو النهي عن الغضب. أي التأكيد على النهي.

من الملاحظ من الأمثلة السابقة أن ضمير الانعكاس يتوافق مع الأفعال وحيدة المقطع،

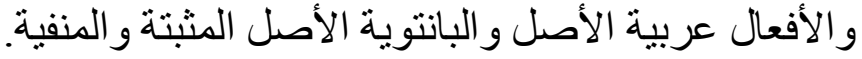

التوافق مع ضمير الغائب (A):

منثال من رواية (Siku Njema): (

Alijifanya kahuzunika sana kutokana na kifo cha mamangu. (Siku Njema, P. $18)$.

$$
\text { - م - تظاهر بالحزن الثديد لموت أمي. }
$$

توافق المعنى الدلالي لضمير الانعكاس في الجملة مع ضمير المفرد الغائب والغرض الدلالي من الانعكاس هو التأكيد على الحدث وهو الحزن وجاء ضمير الانعكاس في كلمة fanya دون لبيان أن الفاعل يتصنع الحزن لنفسه لأن كلمة (fanya) يجعل. أي أن نفسه لا تريد وإنما هو يجبرها على ذلك. أما لو اقترن ضمير الانعكاس بالفعل (fanya) بدون كلمة (fazuni) لكان الحزن نابع من تلقاء نفس الفاعل الغائب أي ليس فيه تصنع. مثال آخر بنفس المعنى الدلالي في رواية (Siku Njema)

- Mwana Saumu aliposikia taarifa ya kupita kwangu alijifanya kama ambaye alifurahi kuliko wengine wote.

26

لما سمعت السيدة ساومو بالخبر مني تظاهرت بأنها أشد فرحا من الآخرين. فالفعل جعلت وبعده أداة نتبيه يبين أنها تتصنع في الفعل. أب أنها تجبر نفسها على أداء هذا الفعل. مثال آخر من رواية (Siku Njema): - مثال 
- Marashi aliyojipaka yalinukia kila alipopita chomboni. (Siku Njema, P. 48).

$$
\text { - م - الطِيب الذي نَطَيَبَ به يفوح كلما مر بالحجرة. }
$$

جاء ضمير الانعكاس (ji) ليؤكد على الحدث وهو التطيب. (paka). وقد نوافق المعنى الدلالي لضمير الانعكاس مع بنية الجملة، والغرض الدلالي من التأكيد على الحدث. أمثلة أخرى من رواية (siku Njema)

- Alijiita Mpendaraha tangu hapo hata jina hilo likawa lake haswa lililosibu. P.65.

- - سمى نفسه مبنداراحا (محب الراحة) إلا أن منذ ذلك الوقت فإن هذا الاسم سبب له

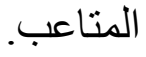

Alikuwa kaharibika vibaya vibaya, anajiuza kama peremende au njugu. P.82. - قد تحطم تماما، وباع نفسه مثل الحلوى أو البندق. أمنظة من رواية (Nasikia Sauti ya Mama)

Akajitwika sanduku lake la mbao na kwenda zake. P. 68.

$$
\text { - - أخفت بنفسها صندوقها الخشبي وذهبت وشأنها. }
$$

Alijitoma nje usiku na kwenda kwa Mwalimu Kikechi. P. 93.

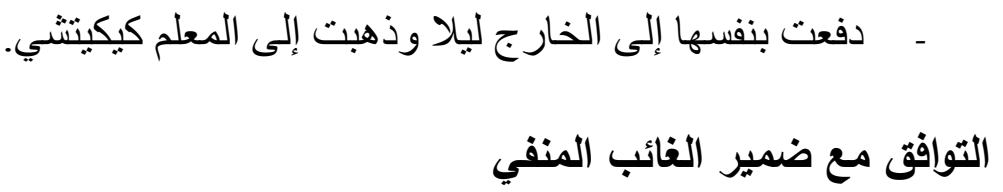

- Ni Kiswahili chenye makosa yaliyozoeleka hadi ya kuwa anayeyafanya hajisikii kama ambaye kakiuka kanuni ya ufasaha wa kusema na sarufi ya lugha. (Siku Njema, P. 106).

- إنها السو احيلية ذو الأخطاء المعتادة، حتى أن من يفعلها لا يشعر في نفسه بذلك، كالذي يخالف بلاغة القول ونحو اللغة. 
جاء ضمير الانعكاس في هذه الجملة في كلمة (hajisikii) ليؤكد على القائم بالحدث. أمنلة من رواية (Nasikia Sauti ya Mama)

- Majirani walisikia tu kilio cha mtoto. Walipofikia mtoto alikuwa kazimia, hajijui hajitambui. P. 42

- سمع الجير ان صرخة الطفل. فلما أتوا إلى الطفل كان في حالة اغماء، لا يشعر و لا يميز.

Alipofika kwake watani, alimkuta mkewe kashika tama hajifai kwa majonzi na mashaka. P. 100.

- ملما وصل إلى موطنه، وجد زوجته في حالة من اليأس ولم تستفد نفسها من الحزن

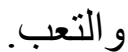

يتضح من خلال الأمثلة السابقة أنه عند تكرار ضمير الانعكاس في فعلين منتاليين، في حالة النفي، وكان الفعلين من أفعال الأحاسيس والشعور، فحينئذ يكون التأكيد في الجملة على فلى القائم

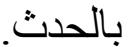

ثانياً: التوافق مع المفرد في باقي الفصائل: أمثلة من مادة البحث من رواية (Siku Njema)

- Licha ya chenene waliolialia na mijipanya iliyoduruduru, mji huo ulikuwa umejiinamia jii. (Siku Njema, P. 124)

- على الرغم من الحشرات التي أحدثت طنينا وجحور الفئران الدائرية، فقد كانت هذه المدينة في الواقع في سكون شديد حقاً.

- Alikuwa mrefu wa kimo na uso wake ulijificha katika msitu wa miwani, sharafa na masharubu. (Siku Njema, P. 90).

- كان طويل القامة ووجهه في الحقيقة كان مختفيا في أحر اش النظارة، وسو الف الثعر و الثشارب. 
- Magharibi ilipofika nikaingia gari moshi liendalo sehemu za Malaba katika mpaka wa Kenya na Uganda. Likajikokota kama konokono. (Siku Njema, P. 104)

- فلما حان المغرب ركبت القطار المتجه نحو مناطق مالابا الواقعة على حدود كينيا وأوغندا. فبدأ القطار يسحب نفسه مثل الحلزون (اسم حيوان).

- Mdundo uliojikaririkariri ulikuwa hivi: p. 34.

$$
\text { - - كان هذا هو اللحن الذي يكرر نفسه دومًا. }
$$

- Baridi shadidi ilienea katika ukumbizo. Sinia iliyokuwa na mshumbi wa ndizi aina ya mkono wa tembo ilitoa mvuke uliojipetapeta katika mwangaza hafifu wa taa ya kandili. P. 35.

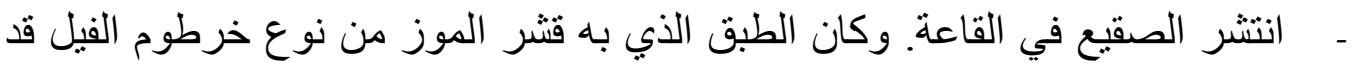
خرج منه بخار مر بنفسه في ضوء خاءع خافت من المصباح.

- Nikanyanyua uso na kuutazama mwezi uliojifaragua angani. P. 40.

$$
\text { - رفعت وجهي ونظرت إلى القمر الذي سطع بوضوح في السماء. }
$$

مثال ما ورد من مادة الدراسة من رواية (Nasikia Sauti ya Mama)

- Je, Kenya itajiangamiza yenyewe kwa ukabila jinsi mtu anavyojiua kwa mikono yake mwenyewe kwa kujitia kitanzi? (Nasikia Sauti y Mama) P. 56.

- - هل ستدمر كينيا نفسها بنفسها بالقبلية كما بقتل الثخص نفسه بيديه انتحارا؟

$$
\text { مما سبق من أمثلة نستتنج الآتي: }
$$

يتوافق ضمير الانعكاس مع ضمائر الفاعل في فصيلة الأشخاص وغيرها من الفصائل إلا أنه يتواجد بكثرة مع فصيلة الأشخاص، ولعل ذلك لأمن اللبس في الكلام. تغير المعنى الدلالي للكلمة (ficha) عندما جاء معها ضمير الانعكاس حيث أن زيادة التأكيد على الفعل قد أدى لزيادة معنى الاختباء إلى حد التخفي. 
karirikariri, petapeta, يلحق ضمير الانعكاس أيضا بالأفعال التي به تكرارا، منل وغيرها. حيث يُعد التكرار في الفعل نفسه تأكيد، وإضافة (ji) يكثف من معنى التأكيد. • صيغة اللزوم مع الفعل الذي يلحق به ضمير الانعكاس يؤدي لزيادة التأكيد على الحدث.(11) عند ذكر الموصول مع ضمير الانعكاس فهو تأكيد على القائم بالحدث. (ب): توافق ضمير الانعكاس مع الجملة في حالة الجمع أولا: التوافق مع الجملة في حالة الجمع مع فصيلة الأشخاص (M-WA) (tu) التوافق مع ضمير جمع المتكلمين ورد التوافق مع ضمير جمع المتكلمين في مادة الدراسة في مثالين فقط من رواية ( Nasikia Sauti ya Mama

- Mimi na ndugu zangu wakubwa, Kuto na Nambuye waliokuwa wameanza kusomea shule moja iitwayo Kikulu tulikuwa bado katika kitovu chetu cha Baraki, tulijikuta tunatangamana na watoto wajuaji wa mjini Kitale. (Nasikia Sauti ya Mama). P. 29.

- - مبدأت الدر اسة أنا و أخوتي الكبار كونو و نامبويا في مدرسة واحدة معا، تُسمى كيكولو

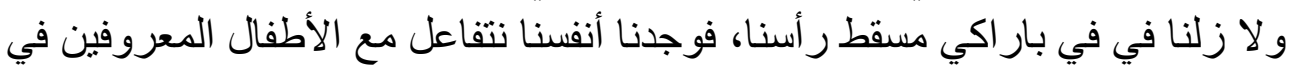
مدينة كيتالي.

- Tulijihimu mapema kulipanda basi la kampuni ya Overseas Trading Company (OTC) lililotupitisha Webuye, Kakamega hadi Kisumu. (Nasikia Sauti ya Mama). P. 61.

- مانتلنا بالفعل مبكر ا وركبنا حافلة شركة أعالي البحار للتجارة ( Overseas Trading و التي مرت بنا على وييويا، وكاكاميجا إلى كيسومو. (Company (OTC)

11 ملحوظة أضافها أدم/ أحمد الثقبي وهي " أظن أن الأداة "ji" تقوم أو تعمل عمل اللزوم في اللغة السواحيلية

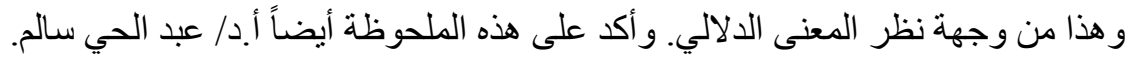


جاء ضمير الانعكاس في كلمة (tulijihimu) ارتحلنا أو انتقلنا والفاعل ضمير جمع للمتكلمين.

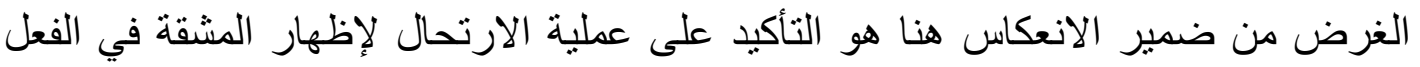

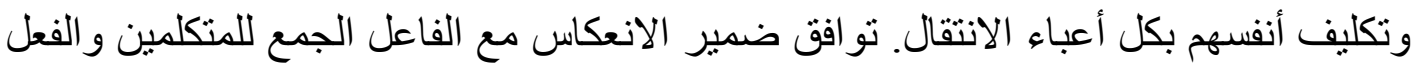
قد أتى بمعنى بلاغي زائد على المعنى الأصلي.

ملحوظة: وهي أن ضمير الجمع للمتكلمين في فصيلة الأشخاص قد يأتي مع ضمير الانعكاس في صيغة الأمر المؤدب نقول مثناً: (Hebu tujiulize). نحب أن نسأل أنفسنا. ضمير الإنعكاس هنا (ji) جاء ليؤكد على القائم بالحدث. التوافق مع ضمير جمع المتكلمين: (TU) المنفي.

- Walakini inasikitisha kuona kuwa wengi wetu hatujifungi vibwebwe kukiendeleza Kiswahili. (Siku Njema, P. 128)

- ولكن من المؤسف رؤية أن أغلبنا ليس لديه الاستعداد النفسي الجيد للنهوض بالسو احيلية.

ضمير الانعكاس جاء في كلمة (hatujifungi) وكلمة (funga) تعني الإغلاق أو الربط الجيد.

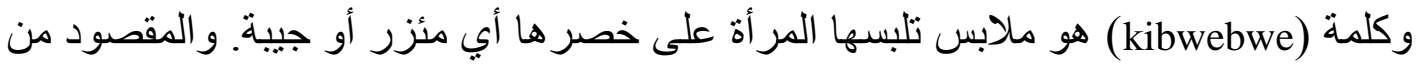
التعبير هو الاستعداد الجيد لفعل أمر ما. مثال ذللك: للكئ

Wanakijiji wamejifunga kibwebwe kwa ujenzi wa afisi ya chama

$$
\text { القرويون استعدو ا تماما لبناء مكتب الحزب." (12) }
$$

فالمعنى مأخوذ من اللغة العربية. (شد المئزر في أمر ما)؛ أب أخذ الأمر على محمل الجد، فتشمر

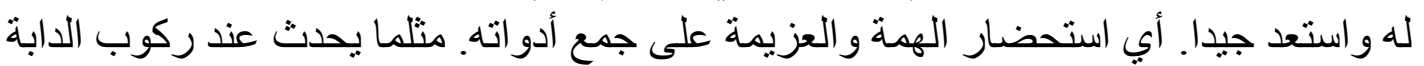

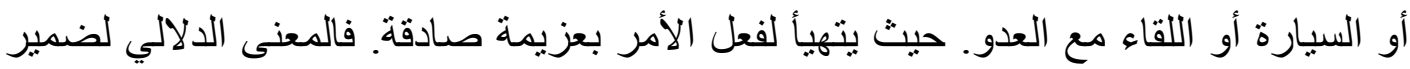

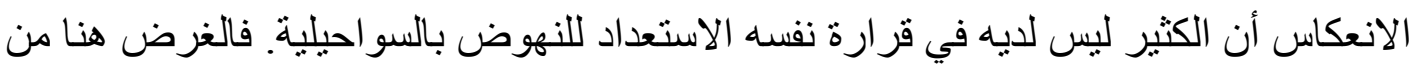

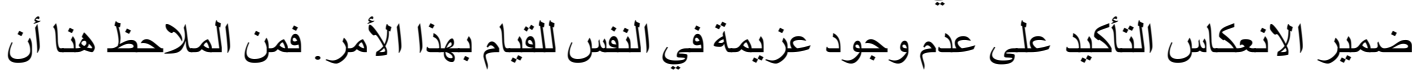

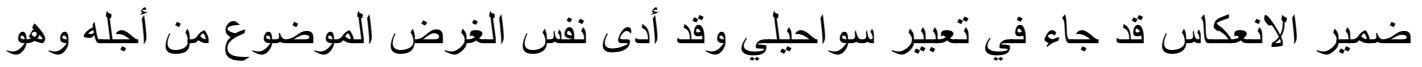

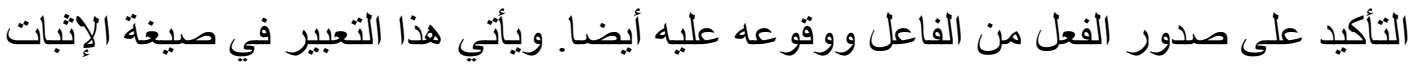

${ }^{12}$ Wamitila, K. W. Kamusi ya Misemo na Nahao, Longhorn Publishers, Kenya, Ltd. Nairobi, 2000, chapa cha Kwanza, 1999, p. 94. 
nitajifunga و وفي صيغة المفرد (hatujifungi vibwebwe) و النفي (tutajifunga vibwebwe) (kibwebwe و الجمع (tutajifunga vibwebwe). مثنال آخر من رواية (Nasikia Sauti ya Mama)

Siku za mtihani zinakaribia kwa kasi. Tumefanya mazoezi ya mitihani ya masomo yote kwenye vitabu vya mapitio vya Malkiat Singh, tumeyesha. Lakini bado hatujiamini. (Nasikia Sauti ya Mama) P.139.

- تقترب أيام الإمتحان بسر عة. لقد تدربنا على امتحانات جميع المو اد في كتب مر اجعات

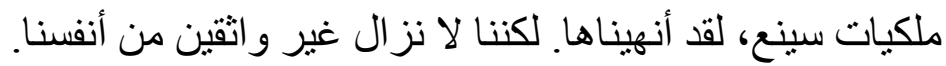

ضمير الانعكاس في كلمة (hatujiamini) نحن أنفسنا غير واثقين من أنفسنا. فالمعنى الدلالي لضمير الانعكاس في الجملة هو أننا على الرغم من الجهود التي بذلناها في المذاكرة إلا أن ثقتنا

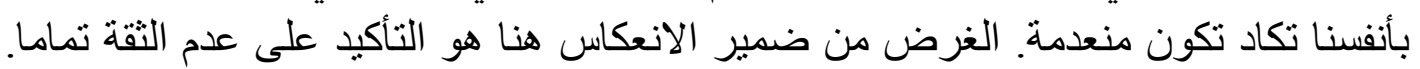

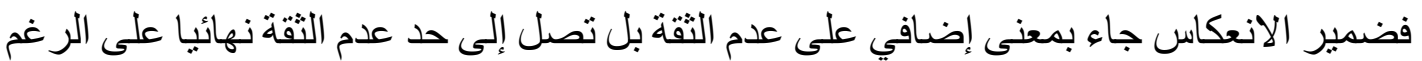

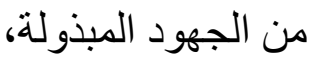

\section{التوافق مع ضمير جمع المخاطبين: (M)}

- Lakini pindi mkijitambua ninyi nani basi mtajua kuwa Kiswahili ni chenu. (Siku Njema, P. 128)

\section{- ل لكن إذا ما علمتم حقاً من أنتم فستعلمون أن السواحيلية هي لغتكم.}

المعنى الدلالي لضمير الانعكاس في الجملة هو أنكم بأنفسم إذا عرفتم من أنتم فستعلمون أن السواحيلية هي لغتكم. الغرض من ضمير الانعكاس هو التأكيد على عملية معرفة النفس. وزيادة في التأكيد وضع كلمة (nyinyi) فهي أيضاً تقبد التوكيد. وتكتب أيضاً (ninyi). وتوافق ضمير الانعكاس مع ضمير المخاطبين الجمع وأيضا مع الثرط وجذر الكلمة (tambua).

Hatutaki mjifie mapema tukuzikeni nyie sisi wazee wenu, nyie ndinyi mpasao kutulilia na kutuzika tuzeekapo na kujifia. (Nasika Sauti ya Mama). P. 30 . 
- لا نريد أن تر هقو ا أنفسهم مبكر ا وندفنكم فنحن مشايخكم، فأنتم بالفعل من سيبكينا ويدفننا

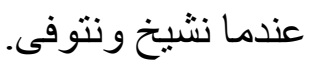

جاء ضمير المخاطبين الجمع في الكلمة (mjifie) يليه ضمير الانعكاس فجذر الكلمة. المعنى الدلالي لضمير الانعكاس هنا طلب عدم الموت فلا تساعدوا أنفسم في الوصول إلى الموت أي فلا تدفعوا أنفسكم نحو الموت مبكرا. الغرض التأكيد على عدم طلب الموت. نوافق المعنى الدلالي لضمير الانعكاس في الجملة وجاء لغرض بلاغي وهو الطلب الإنشائي. أي أن الأمر جاء في صيغة الأمر المؤدب. ليعطي معنى الرجاء والتوسل. التوافق مع ضمير جمع الغائبين: (WA)

Wengi wa wanawake hao walikuwa wamejisetiri barabara ndani ya buibui. (Siku Njema, P. 78).

- أغلب هؤلاء النساء كن يسترن أنفسهن تماما بالنقاب.

Amina na Zwadi wakajikalifu kunitunza na kuniuguza. (Siku Njema, P. 90)

$$
\text { - أمينة وزوادي كلفوا أنفسهم براعيتي وتمريضي. }
$$

- Mathalan F. Johnson na Dr Ludwig Krapf, waliojikusuru kuandika kamusi za awali za Kiswahili. (Siku Njema, P. 128)

- على سبيل المثال إف. جونسون و د. لودوج كراف، أخذوا على عاتقيهما كتابة أول

$$
\text { القواميس السواحيلية. }
$$

- Sijui hadi leo kama baba na naibu wake waliufuata mtaala wa wizara ya elimu au walijiundia mtaala wao wenyewe. . (Nasika Sauti ya Mama). P. 74 / 75

- ل أعلم إلى اليوم إذا كان الاب ونائبه يتبعون منهج وزارة التربيةو التعليم أو أنهم وضعوا بأنفسهم مناهجهم بأنفسهم.

- Wanafunzi wakijishajiisha kwa njia mbalimbali kabla ya mtihani. (Nasika Sauti ya Mama). P. 141 
- - الطلاب يشجعون أنفسهم دوماً بطرق مختلفة قبل الامتحان.

\section{ثانيا: التوافق مع الجملة في حالة الجمع في باقي الفصائل:} مثال ما ورد من مادة البحث في رواية (Siku Njema)

- Tukapasua weu katika magugu na maoteo yaliyojiotea kiholela. (Siku Njema, P. 124).

- شقنا طريقا في الأعشاب و النباتات التي نبتت بنفسها عشو ائيا.

من الملاحظ هنا أن ضمير الانعكاس في كلمة (yaliyojiotea) يؤكد على الحدث، وقد جاء بعد ضمير الانعكاس صفة لتوضح الحدث.

- Jitihada zangu kujinasua toka kwa mnaso wake hazikufua dafu. (Siku Njema, P. 52).

$$
\text { - لم تقلح جهودي بذاتها في الخروج من مكايدها. }
$$

جاء ضمير الانعكاس في كلمة (kujinasua) بمعنى خرج أو غادر وبعد بادئة الفصيلة (ku). فضمير الانعكاس يؤكد على الحدث في الجملة وهو عملية الخروج نفسها. 


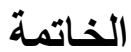

تخلص هذه الدراسة إلى عدد من النتائج والتوصيات نجملها فيما يلي:

المورفيم (ji) يأني في التصغير وفي التكبير بغرض دلالي هو تكثيف المعنى، وإزالة اللبس الصرفي والدلالي الذي ينشأ عند حذفه.

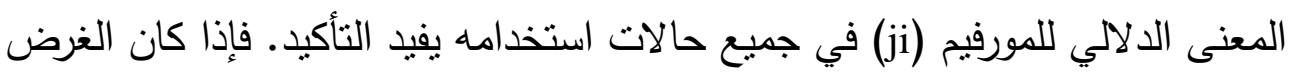

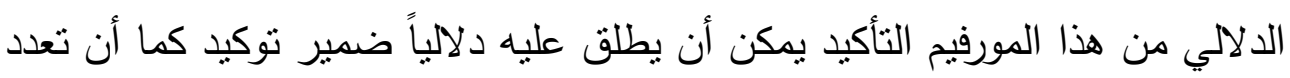
استخداماته النحوية لا يعوق من تسميته بضمير نوكيد.

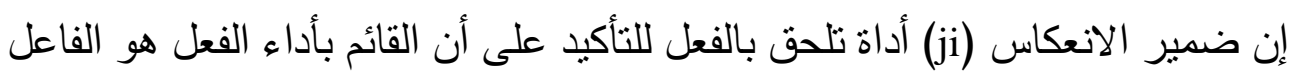
نفسه. ويذكر الفاعل غالبا في الجملة. يقع ضمير الانعكاس قبل جذر الفعل مباشرة في موقع الدفعول به، لعدم تكرار ذكر الفاعل في الجملة لأن المفعول به هو نفس الفاعل في الجملة. ضمير الانعكاس له صيغة واحدة في الإفراد والجمع حيث يتضمن في معناه الإفراد والجمع فإذا كان الفاعل مفردا كان التأكد على ذات الفاعل المفرد وإذا كان جمعا كان النعان تأكيدا على ذات الفاعل الجمع. أي أنه يوافق ما قبله في الإفراد والجمع والتذكير والنأنيث. يثنترط في ضمير الانعكاس حتى يؤدي المعنى الدلالي الموضوع من أجله في الجملة

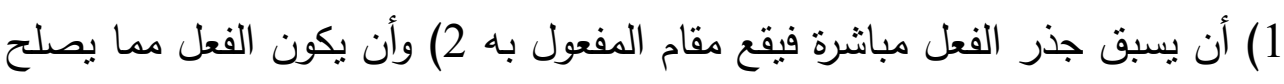
أن يقبل في معناه ضمير الانعكاس، 3) أن يسبقه ضمير فاعل. 4) وأن تحتوي الجملة

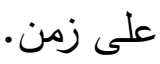
التأكيد على فعل واحد بضمير الانعكاس(ji) ينسحب على بقية الأفعال في الجملة دون ذكر ذللك في الكلام، وذلك يُعد من قبيل البلاغة في اللغة السواحيلية. 
ترى الدراسة أن لضمير الانعكاس دور هام في إضفاء البلاغة على الجملة عن التعبير به في الكلام. حيث يعطي توضيحا زائدا في الكلام وقد يصاحبه في المعنى غرض بلاغي آخر مثل قصد المبالغة أو الإيجاز أو القصر أو تجنب التكرار أو الإقناع...الخ. لإحداث تأثير في المتلقي. يلزم عند استخدام ضمير الانعكاس في الكلام أن يتوافق مع بنية الجملة ومنطقية المعنى الدلالي مع الواقع حتى وإن كانت بنية الجملة سليمة. أي مراعاة المعنى الدلالي العام للجملة.

يتوافق المعنى الدلالي لضمير الانعكاس في الجملة السواحيلية مع الفاعل المفرد والفاعل الجمع في جميع الفصائل بشرط أن يأتي ضمير الانعكاس قبل جذر الفعل قد تأني سوابق أخرى قبل ضمير الانعكاس منل سابقة الموصول، أو ذكر الاسم قبل ضمير الفاعل. وأيضا قد يأني بعد الفعل المشتمل على ضمير الانعكاس ضمير يعبر عن النفس. بغرض زيادة الإيضاح والتأكيد. يكثر مجيء ضمير الانعكاس مع ضمائر الفاعل من فصيلة الأشخاص، ويكثر مجيئه مع أزمنة الماضي في السواحيلية. وخاصة الزمن (1i). من الأغراض الدلالية لضمير الانعكاس: 1) هو إفادة التأكيد على أن الفاعل قد قام بالفعل. 2) إزالة الإبهام واللبس في الجملة، وذلك لتحاثي سوء الفهم أو اللبس. 3) يفيد الاختصاص أي اختصاص الفاعل بالقيام بالفعل دون غيره، 4) توضيح المعنى وبيانه. 5) إضافة بلاغية للجملة. 6) البعد عن التكرار والحشو . الصيغة التركيبية النحوية الأصلية التي يأتي عليها ضمير الانعكاس هي ضمير فاعل مفرد أو جمع + زمن + ضمير الانعكاس + جذر الفعل. وقد تأني سوابق أخرى تقوي المعنى الدلالي لضمير الانعكاس منل الموصول. 
إذا ما حذف الزمن مع وجود الفاعل وضمير الانعكاس تحول الفعل إلى أمر مؤدب في صيغة توكيدية بلاغية. يأتي ضمبر الانعكاس في الجمل الخبرية والإنشائية وكذا الجمل البسيطة والمركبة. ويأتي في أول الجملة ووسطها وآخرها. على حسب الصياغة للجملة. يأتي ضمير الانعكاس (ji) على صورتين: إما مؤكدا للفاعل على قيامه بالحدث، وإما مؤكدا على الحدث بأن من قام به هو الفاعل الذي يعود عليه ضمير الانعكاس. ضمير الانعكاس يلحق بالفعل الذي يدل على الإحساس والثعور عندما تتكرر الأفعال في الجملة. كلمة نفس (mwenyewe) بعد ضمير الانعكاس في الأفعال الدالة على الإحساس والشعور فإنما هي تدل على أن ضمير الانعكاس جاء ليؤكد على الفاعل. توافق المعنى الدلالي لضمير الانعكاس في جملة الفاعل المفرد المشتملة على نفي يكون التأكيد فيها على نفي ضمير الفاعل في المقام الأول ثم بعد ذلك التأكيد على الحدث سواء مع أفعال الأحاسيس والثعور أو مع غيرها من الأفعال. تضاف كلمة (mwenyewe) قبل ضمير الانعكاس إلى الجملة عند قصد التأكيد على القائم بالحدث مع فعل ليس من أفعال الإحساس والثعور . يأتي ضمير الانعكاس بعد (kama) التي تقيد التشبيه للتأكيد على الحدث. كلمة نفس لا تأتي مع الأفعال التي تقيد الإحساس والثعور التي تحتوي على ضمير توكيد.

قد يأتي ضمير الانعكاس مع جذر الفعل فقط في صيغة الأمر للتأكيد على الحدث. ضمير الانعكاس يتو افق مع الأفعال وحيدة المقطع، والأفعال عربية الأصل والبانتوية

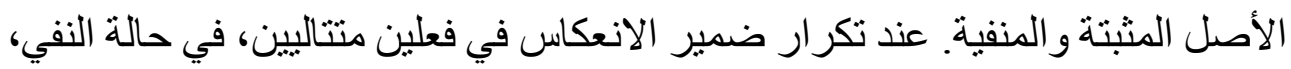

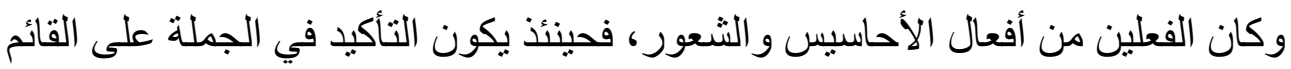
بالحدث. 
قد يتغير المعنى الدلالي للكلمة عند إضافة ضمير الانعكاس لها فتحمل معنا أعمق

$$
\text { وأدق. }
$$

التعدي واللزوم مع الفعل الذي يلحق به ضمير الانعكاس يؤدي لزيادة التأكيد على

$$
\text { الحدث. }
$$

عند ذكر الموصول مع ضمير الانعكاس فهو تأكيد على القائم بالحدث. ضمير الانعكاس قد يلحق بالتعبيرات السواحيلية ليؤكد على المعنى. توصي الدراسة بالمزيد من اجراء الدراسات على الضمائر في اللغة السواحيلية. دراسة وصفية تحليلية في ضوء مناهج علم اللغة. 


\section{ثبت المراجع}

\section{أولاً: المراجع العربية}

سهير بدر، "البحث العلمي" دار المعارف، القاهرة، 1982م.

• شوقي ضيف، "المدارس النحوية"، القاهرة، 1976.

• عبد الحليم بن عيسى، "القواعد التحويلية في الجملة العربية"، دار الكتب العلمية،

بيروت، لبنان، ط1 ، 2011م.

• عبد الحي أحمد محمد سالم: "اللواحق الاشتقاقية واللواحق التصريفية فى اللغة

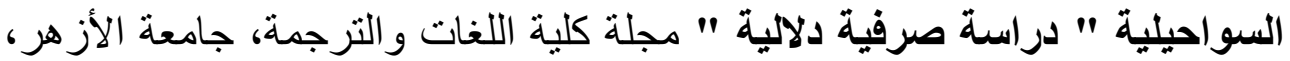

$$
\text { العدد 39، 2006م. - - 2006. }
$$

• عبد الحي أحمد محمد سالم، "قواعد اللغة السواحيلية"، جامعة الأزهر، كلية اللغات و الترجمة، قسم اللغات الإفريقية، ط4 ، 2018. عبد العزيز شرف، "اللغة الإعلامية علم الإعلام اللغوي" الناشر المركز الثقافي

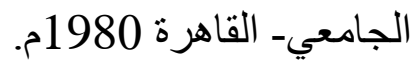
• عبده الراجحي: "النحو العربي والدرس الحديث"، دار النهضة العربية للطباعة و النشر، بيروت. (د.ط)، 1979

علي علي أحمد شعبان، "التكبير والتصغير في اللغة السواحيلية"، مجلة كلية اللغات و الترجمة، جامعة الازهر ، المجلد أو العدد 18، 1988

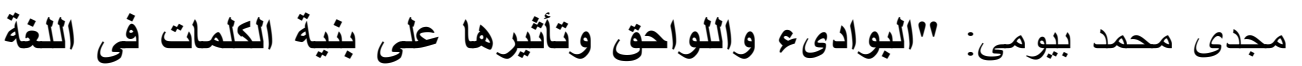

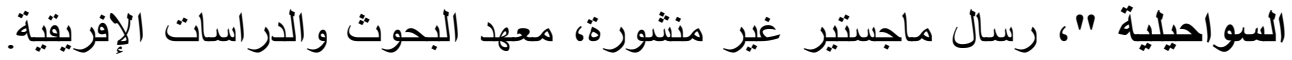
جامعة القاهرة. القاهرة 1982م. محمد أبو موسى: "خصائص التراكيب دراسة تحليلية لمسائل علم المعاني"كلية اللغة

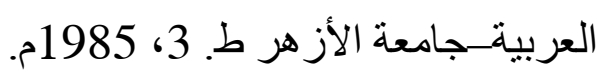
محمد طلبة عبيد، "المورفيم فى اللغة السواحيلية المعاصرة، دراسة تطبيقية على الفعل"، رسالة دكتور اه غير منشورة، كلية الألسن، جامعة عين شمس، القاهرة 1994م. • محد علي الخولي: "قواعد تحويلية للغة العربية"، المملكة العربية السعودية، الرياض، دار المريخ للنشر، ط 1، 1981م. 
محمود سليمان ياقوت، " منهج البحث اللغوي" دار المعرفة الجامعية، الإسكندرية، 2000م.

نعوم تشومسكي، "آفاق جديدة في دراسة اللغة والعقل"، ترجمة عدنان حسن، منتدى

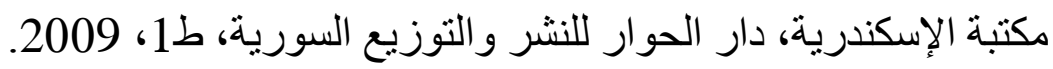

ثانياً: المراجع الأجنبية

- Ashton , E.O. ( 1944-1974): " Swahili grammar (Including Intonation)"Longman.

- Besha, Ruth Mfumbwa. "Utangulizi wa Lugha na Isimu", Dar es Salaam University press, Dar es Salaam, 1994.

- Maw,Joan"Sentences in Swahili:Astudy of their internal relationships" SOAS. University of London 1969.

- Mohamed A. Mohomed; "Sarufi mpya", Press and Publicity Centre, Dar-esSalaam, Tanzania 1986.

- Mohamed Abdulla Mohamed, "Modern Swahili Grammar", East African Publishers,, 2001.

- Mwansoko,H.J.M.(1991):"Mitindo ya Kiswahili Sanifu" Dar es salaam university press, Dar es salaam .

- Walipora, Ken "Nasikia Sauti ya Mama"Longhorn Publishers (K) Ltd., Nairobi, Kenya., chapa cha kwanza, 2014. Toleo, 2016. P 71.

- Walipora, Ken "Siku njema"Longhorn Publishers (K) Ltd. , Nairobi, Kenya., chapa cha kwanza, 1996. Toleo, 2012. P 18.

- Wamitila, K. W. "Kamusi ya Misemo na Nahao", Longhorn Publishers, Kenya, Ltd. Nairobi, 2000, chapa cha Kwanza, 1999, p. 94.

- Wesana- Chomi E.; "Sarufi Tangulizi ya Kiswahili, Sarufi Maumbo", Idara ya Uchapishaji, Tasisi ya Lugha, Sebha, Libya 1989.

- Wilson,Peter " simplified Swahili" Longman,1985. 